\title{
REGISTROS DE LA EXPRESIÓN POBLACIONAL DURANTE EL III MILENIO EN ANDALUCÍA OCCIDENTAL
}

\author{
SETTLEMENT EVIDENCE FOR THE III MILLENNIUM BC IN WESTERN ANDALUSIA
}

\author{
por \\ ROSARIO CRUZ-AUÑON BRIONES \\ EUSEBIO MORENO ALONSO \\ PILAR CACERES MISA
}

\begin{abstract}
RESUMEN En el III milenio se asiste a la más antigua eclosión demográfica de este sector regional, humanizándose toda una amplia gama de paisajes, incluso algunos de ellos por primera vez. Tal circunstancia necesita ser explicada y no sólo en base a esa cuantitativa expansión poblacional, o a la cualitativa expresión cultural, sino que habrá que intentar reconocer qué opciones la generaron y cómo un milenio después se llega a resultados diferentes. En este trabajo partimos de una recopilación y valoración de la documentación existente, hasta hoy desconectada por las diversas razones que la han determinado, con la intención de patentizar dónde y en qué sentido ha de reforzarse la investigación.
\end{abstract}

\begin{abstract}
In the third millenium we presence the first significant demographic growth of this region, along with an expansion of the population towards new territories,some of which had never been inhabited before. This phenomenon should not be explained only by the quantitative population expansion nor by the qualitative cultural expression, but we ought to find why this expansion was generated and how was the development to a different situation in the next millenium. This paper is based on a compilation and valuation of the available published materials on the subject, dispersed until now due to the various circumstances and reasons that created them; our aim is to make evident where and in which directions the research must be reinforced.
\end{abstract}

Al abordar el estudio de la Edad del Cobre en Andalucía Occidental nos encontramos como la mayoría de la documentación tradicional se refiere al mundo funerario, mientras que el poblamiento, el verdadero mundo de los vivos contaba con escasas alusiones. Afortunadamente esta circunstancia ha cambiado en pocos años generando con relativa rapidez una gran cantidad de publicaciones fruto de distintos proyectos de investigación. 
Es por ello que en este trabajo nos proponemos recopilar la documentación referente a la expresión poblacional, desde una óptica casi exclusivamente cuantitativa, y sin entrar en esta ocasión en profundidad en los debates metodológicos que intentan explicar la génesis o razón de ser de esta etapa cultural, ni en las problemáticas y artificiales cronologías trifásicas (Cobre Inicial, Medio y Final) o bifásicas (Precampaniforme y Campaniforme) por las que tradicionalmente se viene explicando su desarrollo interno. $\mathrm{Y}$ aunque ocasionalmente hoy cuestionemos algunas interpretaciones o tendencias interpretativas, pensamos que realmente son ciertos registros los que carecen de un cuestionamiento más totalizador si queremos reconocer el proceso histórico que culminó con la formación de sociedades complejas y sus consecuencias.

En este sentido, nosotros mismos somos los primeros en asumir tal compromiso desde nuestro proyecto de investigación en el Bajo Valle del Guadalquivir. Tenemos la confianza que en pocos años, y a la luz de otros proyectos en curso, podremos articular mejor el cúmulo de dicha información.

Aunque no somos partidarios de establecer límites geográficos siguiendo los actuales límites jurisdiccionales, en aras de una mejor organización en la presentación del tema, vamos a tratar exclusivamente a las provincias de Huelva, Cádiz y Sevilla.

En el extremo noroccidental de este marco geográfico se sitúan los PICOS DE AROCHE. Los estudios de A. Pérez Macías (Pérez, 1987) sugieren la llegada del contingente humano al generalizarse las ocupaciones al aire libre, puesto que la geología local no permite la formación de cavidades, como ocurre en la Sierra de Aracena, donde sí se han documentado poblamientos en cuevas (Pérez, 1986; Pérez, Rivero y Cruz-Auñón, 1990; Borja y Gómez, 1991).

En esta zona, las evidencias ocupacionales las encuentra en alturas cercanas a las vías fluviales, el Múrtiga y el Chanza.

- El Múrtiga, transcurre muy encajonado en materiales primarios y en principio no parecía ofrecer suficientes atractivos, pero aporta un buen número de asentamientos, que incluso se extienden por sus afluentes. Estos ocupan alturas medias, aprovechando ocasionalmente bancales de mampuestos ciclópeos que forman altozanos con posibilidades defensivas naturales, circunstancia más acentuada en Sierra Herrera, donde los bloques ciclópeos enlazan con los graníticos adquiriendo el aspecto de una muralla. En otros casos, los asentamientos parecen más desprotegidos y son precisamente aquellos relacionables con los pocos espacios de vega. Y, por el momento, tan sólo un asentamiento se emplaza junto al río-San Sixto-, donde sus materiales apuntan a cronologías tardías.

Así, el río no parece ser el principal eje de atracción, pues aparecen zonas pobladas frente a espacios vacíos, o como ocurre más claramente en los afluentes, que los asentamientos no están cara a éstos.

- El Chanza, por el contrario, ofrece zonas más amplias de vega y de óptimas posibilidades agrícolas, aunque también ese relieve alcanza altura. Los asentamientos, igualmente, los encontró ubicados en altitudes medias, con excepción de el de Pico de los Ballesteros, en lo más alto de la serranía. La mayor concentración corresponde a solanas o llanos, y ahí diferencia tres agrupamientos relacionándolos con caminos naturales:

- primer grupo, se sitúa en el único paso hacia el valle desde el norte.

- segundo grupo, en comunicación con zonas de cierta importancia, como el Andévalo.

- y un tercer grupo, más alejado -Pico de los Ballesteros-, significaría el paso de los anteriores hábitats a menor altura, y así explica la posible correlación cronológica entre sus materiales.

En general se presentan como poblados de pequeñas dimensiones, no más de $100 \mathrm{~m}^{2}$, incluso algunos asentamientos resultan tan reducidos que parecen corresponder a una sola vivienda, lo que ha 
sido interpretado por el autor como el resultado de un control del río, entendido como vía de comunicaciones, a base de cabañas vigías. Interpretación a tener en cuenta pero que necesita de otro tipo de definición dado el estado actual de la cuestión. En contrapartida, sólo en el Chanza ve poblados un poco mayores.

La única información sobre las estructuras de habitación proviene de lo dejado al descubierto por las roturaciones forestales. Apunta que las viviendas serían de tendencia circular, con zócalos de piedra y posiblemente estarían cubiertas con materiales ligeros según las improntas de ramajes en el barro. Otra posibilidad señalada es que en su totalidad fueran de materiales perecederos. Y un último tipo de hábitat documentado corresponde a los covachos, no superiores a los $3 \mathrm{~m}$. de profundidad, en los grandes bloques graníticos de las laderas de las Peñas de Aroche.

A. Pérez Macías explica el poblamiento de ambas cuencas en base al potencial económico del medio, así en el Chanza la expresión poblacional queda determinada por las posibilidades de mantener una economía agrícola-ganadera; junto a la explotación del bosque como evidencian los talleres pulimentados. Además, y nos parece de interés remarcar, se asiste a una concentración mayor de ocupaciones en zonas de paso, tanto en contacto hacia el Norte como hacia el Sur. Para el caso del Múrtiga y afluentes sugiere una asociación de asentamientos en relación con la explotación de la minería, al estar los asentamientos exclusivamente vinculados con importantes venas filonianas, puesto que en zonas sin ellas no se registran. Estos productos, por demás, encontrarían fácil salida a través de ciertos núcleos del Chanza.

Posiblemente, las poblaciones Neolíticas de la Sierra de Aracena (Camalich, Martín y Arco, 1984; Pérez, Rivero y Cruz-Auñón, 1990) contribuyeron en el poblamiento de este ámbito, donde participarían en la dinámica de una nueva política socio-económica, reactivada en las relaciones intergrupales a una escala más compleja.

Hacia el sur de esta comarca se extiende EL ANDEVALO, una prolongada superficie donde el zócalo Occidental de Sierra Morena ha sufrido un modelado natural de aplanamiento, y por el que transcurre una red fluvial no excesivamente caudalosa, formando ocasionales meandros, recodos, con aportes de gravas y arenas. La historia tectosedimentaria aún no está claramente definida para estos momentos del Holoceno lo que nos impide plantear con mayor seguridad las ocupaciones humanas. De todas formas se presenta como una zona rica en recursos: agrícolas, ganaderos, forestales, mineros etc.

Se ha señalado un anterior poblamiento tardoneolítico, ejemplarizado en los yacimientos de Las Chapas y Arroyo Casas, ubicados en altozanos fácilmente defendibles y dotados de amplia visibilidad, patrón de poblamiento que será heredado en la Edad del Cobre (Piñón, 1986; 1987c).

De momento, el mejor asentamiento conocido para la Edad del Cobre es el Cabezo de los Vientos (Santa Bárbara de Casa) (Piñón, 1987a; 1987b; 1987c; 1989); además de algunos talleres líticos (Vallespí, Ramos y Castiñeira, 1988; Castiñeira, Castiñeira, Ramos y Vallespí, 1988), con ciertas diferencias respecto a los conjuntos de áreas próximas (Vallespí, Ramos y Pérez, 1988).

En dicho poblado, de fundación "ex novo", se documentan dos momentos de ocupación, según su excavador: Los Vientos I, con cabañas entre 3 y $4 \mathrm{~m}$. de diámetro, parcialmente excavadas en la pizarra basal ceñidas por débiles zócalos de piedra y erigidas con ramajes embadurnados de barro. Los Vientos II está representado por un recinto amurallado con bastiones y entrada bien protegida. Su espacio interior queda reducido a unos $30 \mathrm{~m}$. por $20 \mathrm{~m}$. en sus ejes, no excesivamente grande.

Se ha interpretado como una comunidad rural básicamente dedicada a las actividades agropecuarias en la Raña y, a pesar de ser una zona con posibilidades mineras, carece de registros indicadores de tal actividad (Piñón, 1987b), aunque la necrópolis asimilada - La Zarcita- ha aportado algunas piezas 
metálicas (Piñón, 1989). Por el contrario, los talleres líticos registrados en la zona son considerados como manifestación de una explotación temporal del sílex dedicada a la elaboración de instrumentos subsidiarios de la tecnología desarrollada para las actividades mineras (Vallespí, Ramos y Castiñeira, 1988).

Igualmente se han destacado las extraordinarias condiciones estratégicas del Cabezo de Los Vientos en cuanto al dominio visual que abarcaría: el suave paisaje de colinas del sector occidental del Andévalo; las vías que canalizan los contactos hacia la zona del Chanza; así como el campo de La Raña (Piñón, 1987c; 1989).

Estas valoraciones puntuales del poblado serán la base para su planteamiento de un patrón de asentamiento diferenciado en esta área onubense (Piñón, 1987c; 1989). Un patrón de asentamiento que, en definitiva, queda fundamentado exclusivamente en un "..interés geo-estratégico (vías de comunicación, riqueza agrícola)..” (Piñón, 1987c: 321; 1987a: 63; 1989: 125).

F. Piñón, así pues, basa sus interpretaciones en la potencialidad agropecuaria del medio y en unas ubicaciones estratégicas supeditadas a los factores económicos supuestos. Las estimaciones sobre cualquier intervención de factores político-sociales, aunque las sugiere, normalmente no quedan bien clarificadas ni asumidas (Piñón, 1987b; 1987c; 1989).

El desconocimiento actual de otras ocupaciones en esta zona, que debió estar bien poblada, según la dispersión de enterramientos (Cabrero, 1985a; 1986), nos dificulta ponderar el papel que desarrollaría esta pequeña ciudadela fortificada en la organización socio-económica del Andévalo, a pesar de su aspecto "rural" y dimensiones. Por lo que en este caso, el concepto de Rango-Tamaño sería motivo de contrastación con otros poblados aún por conocer.

Al sur del Andévalo, nos encontramos con LA DESEMBOCADURA DEL TINTO Y ODIEL Y EL LITORAL ONUBENSE. Este litoral hacia el 3.000 a. de C. sufrió un relativo descenso de $2 \mathrm{~m}$. favoreciendo con ello el desarrollo de la deriva del litoral, ya iniciado con el anterior rebaje marino; asistimos por tanto a la formación de flechas, islas-barreras y algunas lagunas. En la Laguna de Las Madres, estudios palinológicos comprueban la existencia de una zona de parque, seguida de otra de bosque que, precisamente a partir del 2.500 a.de C., empieza a deforestarse de forma intensiva (Menéndez-Amor y Florschutz, 1973). En cuanto al estuario de estos ríos aún quedan por resolver anteriores movimientos que nos permitan entender variaciones en las líneas de costa y sus posibilidades poblacionales.

La ocupación aquí es desde el Neolítico (Piñón y Bueno, 1988), y más aún para el litoral (Piñón y Bueno, 1985; Piñón, 1988) si bien, con las localizaciones de la Edad del Cobre parece registrarse un ligero desplazamiento hacia el actual estuario Tinto-Odiel (Garrido, 1971; Martín, Gómez, Alvarez, y Chaves, 1985).

Los asentamientos conocidos se limitan exclusivamente a: Papa Uvas (Garrido, 1971; Martín, 1985; 1986a; 1986b; 1987; Martín, Gómez y Consuegra, 1990a; 1990b); El Rincón (Garrido, 1971) y La Dehesa (Amo, 1976). Además de localizaciones de talleres líticos atribuídos en la bibliografía al Neolítico (Piñón, 1986), aunque igualmente pueden ser de momentos posteriores.

Para El Rincón, situado en un espigón, sólo se documentan evidencias superficiales de fondos de cabaña y depósitos de desechos, primordialmente de origen marino. Más contravertido, si cabe, resulta el yacimiento de La Dehesa (Lucena del Puerto), pues M. del Amo le atribuye una extensa cronología, Neolítico-Bronce I, mientras que en una bibliografía posterior sólo se reconoce como Neolítico (Piñón y Bueno, 1985).

Una información más amplia se refiere a Papa Uvas, señalándose unos orígenes Neolíticos. Las variadas estructuras de este yacimiento, excavadas en suelos margosos y calizos, presentan una proble- 
mática funcional que aún no ha quedado clarificada, puesto que en los estudios hasta ahora publicados se patentizan diversas interpretaciones sin haber llegado a pronunciarse por alguna de ellas de manera definitiva.

Es el caso de las estructuras "alargadas" o zanjas, sobre las que se han formulado diversas posibilidades funcionales, que van desde considerarlas basureros, viviendas, drenaje o desagüe, trampas para cazar, rediles para el ganado o fosos defensivos, aduciendo para cada posibilidad los razonamientos necesarios para aceptar o no las diferentes funcionalidades. Aunque parece considerarse esta última hipótesis como la más probable (Martín, 1985; 1986b; 1987).

En cuanto a las estructuras de hábitat en un primer momento fueron encuadradas entre las circulares (Martín, 1985), llegando a localizarse hasta catorce fondos de cabaña (Martín, 1986a). Posteriormente, la funcionalidad inferida para estas estructuras circulares comprende desde silos, pozos de ofrenda, horno y vertedero o pozo de ablación, sin inclinarse decididamente por alguna (Martín, 1986b), mientras que las estructuras de habitación parecen definirse como suelos de ocupación en un hábitat al aire libre (Martín, 1986b; Martín, Gómez y Consuegra, 1990a).

De momento, y ante los pocos poblados conocidos en el litoral onubense, es difícil entrever un diseño de la ocupación del territorio y qué relación mantienen entre sí tales localizaciones. Lo que sí parece estar claro es que desde el Neolítico, el hombre encontró en este litoral un medio favorecedor para cubrir sus necesidades alimenticias y artefactuales. Así, explotan los diferentes nichos ecológicos que les oferta la tierra (economía básicamente ganadera con unos aportes cinegéticos poco importantes), a lo que se suma el aprovechamiento de la costa (recolección de moluscos en general y selectiva de alguno de ellos) (Martín, 1986b).

Hacia el este de la red fluvial Tinto-Odiel se desarrolla EL CONDADO, una campiña originada a partir del modelado de dichos ríos, con fallas escalonadas, pequeños glacis de vertientes y terrazas fluviales (Díaz, 1987).

La información de asentamientos para esta zona, igualmente escasa, proviene de registros superficiales y sin actividad arqueológica sobre ellos, a excepción de San Bartolomé de Almonte (Fernández, 1982; 1983; Ruiz y Fernández, 1986). Siendo las ubicaciones documentadas Fuente Vieja (Paterna) (fruto de nuestras prospecciones), Cruz del Aguardo y las imprecisas evidencias aportadas por dos restos campaniformes (Paterna) (Rufete, García y García, 1988).

De estos, nos resulta interesante destacar su posición estratégica para desarrollar un papel de contacto y/o control sobre ciertas actividades, tales como comerciales y posiblemente metalúrgicas. En efecto, se hallan en la confluencia de importantes vías de comunicación, conectando las zonas fluviales y costeras con los yacimientos mineros de la Sierra.

Un camino podría ser la cuenca del Río Tinto, que realmente tuvo actividad como evidencian los talleres (Castiñeira, Castiñeira, Ramos y Vallespí, 1988); y los enterramientos (Rivero, Cruz-Auñón y García, 1988; Pérez, Lorenzo, Pérez, 1988). Y el otro, la tradicional vía minera Aznalcóllar -donde se han documentado asentamientos calcolíticos, aunque sin actividad minera corroborada hasta ahora (Hunt, 1991)- Tejada, San Bartolomé, El Rocío de importancia durante el Bronce (Fernández, 1986; Ruiz y Fernández, 1986)) y que probablemente ya empezara a utilizarse en el Cobre. Esta ruta a su vez resulta de fácil conexión hacia el este con el importante poblado de Valencina de la Concepción (Escacena, 1983) y hacia el oeste con el Andévalo.

Siguiendo con el litoral Atlántico, nos encontramos con LAS MARISMAS DEL GUADALQUIVIR, que hace unos 5.000 años constituía un gran golfo marino; el río desembocaría a la altura de 
Coria del Río (Sevilla) quedando su margen derecha ocupada por la gran extensión de marismas, con unas condiciones, al parecer, no muy óptimas de habitabilidad. De hecho tan sólo tenemos documentado el campo de silos de Puebla del Río (Carriazo, 1966; 1974); el yacimiento de La Marismilla (Puebla del Río, Sevilla) (Escacena, 1987a; 1987b; Escacena y Lazarich, 1985; Escacena y Rodríguez, 1988; Escacena, Rodríguez y Alonso, 1990) y Las Marismas, en Aznalcázar (Rodríguez de Guzmán y Cáceres, 1991).

Según J. de Mata Carriazo, al menos una de las estructuras puede asimilarse a un fondo de cabaña con muros de adobes, mientras que las restantes, varios centenares, los interpreta como silos y que, dada la cantidad de los mismos y su capacidad de almacenaje, plantea que quizás estuvieran destinados a la comercialización por el río del grano cosechado. También es verdad que advierte una larga perduración de los mismos, incluso hasta épocas medievales.

Por otra parte, para el yacimiento de La Marismilla, en un primer momento, se barajaron hipótesis funcionales como alfar, lugar de culto o manifestaciones rituales, enterramiento, cocedero de pescado y/o marisco y depósito intencionado, así como también se propusieron hipótesis sobre su cronología, en el IV milenio a. C., y sobre su origen en el norte de Africa, con unas innegables relaciones con la cultura badariense egipcia (Escacena, 1987a; 1987b; Escacena y Lazarich, 1985).

Finalmente, parecen haberse desestimado estas posibilidades, definiéndose firmemente como una salina de carácter temporal fechada provisionalmente hacia el 3.000 a.C. (Escacena y Rodríguez, 1988; Escacena, Rodríguez y Alonso, 1990). Ambas consideraciones, la funcional y la cronológica, necesitan de mayor precisión, como igualmente manifestó F. Piñón (Piñón, 1987a).

En LA MARGEN IZQUIERDA DEL GOLFO DEL GUADALQUIVIR contamos con una documentación más amplia en virtud a la realización de dos Cartas Arqueológicas (Caro, 1982; 1991; Lavado, 1990); y alguna actividad de excavación (Caro, Acosta, Escacena, 1987).

El paisaje oferta cerros de altitudes medias aislados en la confluencia de las aguas marinas y fluviales, de tal forma que las condiciones de habitabilidad parecen ser mejores que al otro lado del Golfo.

Para momentos precedentes a la Edad del Cobre, los primeros estudios de A. Caro establecen como poblamiento más antiguo en la zona el originado por un desplazamiento de comunidades neolíticas desde la Sierra de Gibalbín conformando un hábitat al aire libre (Caro, 1982; 1985). Tras el registro de materiales y estructuras encuadrados en el Epipaleolítico y Neolítico (Caro, Acosta y Escacena, 1987), los planteamientos iniciales se han modificado sustancialmente.

A este respecto, propondrá, en base a la diversidad del medio ambiente, una "dualidad cultural" durante el Neolítico en el Bajo Guadalquivir, por lo que apreciará un proceso de neolitización diferenciado entre las zonas serranas de Cádiz y las costeras de las marismas, fundamentado en esta última zona en un desarrollo a partir de enclaves y poblaciones epipaleolíticas (Caro, 1991).

Para la Edad del Cobre se ha documentado un gran incremento poblacional a través del mayor número de localizaciones, tanto en el borde de la marisma como al interior. Las explicaciones en relación a esta ocupación giran en torno a la mayor o menor importancia económica del Golfo.

A. Caro lo revalora por suponer una apertura hacia el Atlántico y un fácil acceso desde el Valle, controlando la navegación marismeña y amplias zonas terrestres. Además, destaca el Golfo como una de las principales fuentes de recursos, ante los abundantes restos de moluscos y las posibilidades de explotar pesca y sal. Y así, en segundo lugar señala una rica campiña en la que se desarrollarían las actividades agrícolas y ganaderas (Caro, 1982; 1985; 1991).

Por su parte M. ‥L. Lavado prefiere destacar su orientación al medio físico terrestre, en base a unas ubicaciones estratégicas resguardadas de la costa. Así pues, sugiere la mayor relevancia para la agricul- 
tura, considerando el aprovechamiento de las marismas como un complemento económico (Lavado, 1990).

Así pues, estamos ante explicaciones económicas sensiblemente opuestas y sin una base empírica amplia que avale una $u$ otra.

Ascendiendo por el Guadalquivir, nos encontramos con el término municipal de Puebla del Río, donde tradicionalmente se viene ubicando la antigua desembocadura del río aunque, bien es verdad, necesitamos que se especifique geomorfológicamente el comportamiento del estuario durante el tercer milenio, para así entender mejor la ocupación humana.

En ese mismo lado derecho, se eleva sobre la depresión del valle LA CORNISA DEL ALJARAFE donde una información global se debe a los estudios de J.L. Escacena (Escacena, 1983), así como a las investigaciones realizadas en Valencina de la Concepción (Ruiz, 1983; Fernández y Ruiz, 1978; Fernández y Oliva, 1980; 1985; 1986; Fernández, 1984; Murillo, Pérez, Blanco y Larrey, 1987), más alguna información de hallazgos puntuales (Buero, Guerrero, Iglesias y Ventura, 1978).

Para J.L. Escacena el papel predominante que tenían las marismas para explicar el poblamiento en sus bordes lo ocupa ahora el río Guadalquivir, por cuanto se refleja una intencionada cercanía al río, como ya señaló D. Ruiz Mata (Ruiz, 1975a; 1975b; 1983), motivada principalmente por las actividades comerciales que facilitaría el mismo, ya que descarta las posibilidades agrarias, tanto por la calidad de las margas terciarias dominantes en el reborde del Aljarafe como por los problemas de inundación de la vega y las graveras de las terrazas fluviales inferiores (Escacena, 1983).

Por lo que la ubicación de los poblados se definirá por la selección de las alturas próximas al río, dominando también las entradas a las vías de comunicación terrestres hacia el interior del Aljarafe y Los Alcores. Consecuentemente con estas argumentaciones le atribuye un lugar secundario al aprovechamiento económico de estas comarcas interiores -madera, pastos y productos silvestres de recolección temporal- (Escacena, 1983).

En este reborde parece que existió un despoblamiento desde el Paleolítico Inferior y es precisamente en la Edad del Cobre cuando va a ocuparse intensamente, contabilizándose cerca de una decena de yacimientos (Escacena, 1983).

De todos ellos, se ha excavado el Cerro del Carambolo y Valencina de la Concepción. Del primero, tenemos noticias de fondos de cabaña, posiblemente "Neoeneolíticos" y asemejándolos a los de Puebla del Río (Carriazo, 1973; 1974).

El segundo yacimiento, en uno de los lugares más altos de la comarca, ha aportado varios tipos de estructuras tales como: cabañas, silos, pozos, zanjas y un horno, además de las funerarias (Obermaier, 1919; Carriazo, 1961-1962; Collantes, 1969; Fernández y Ruiz, 1978; Cabrero, 1985b; Murillo, CruzAuñón y Hurtado, 1991; Belén, 1991). En este poblado las interpretaciones funcionales de las diversas estructuras parecen más decididas, en especial en lo que respecta a las zanjas. Estas, en un primer momento, se valoraron como conducciones de agua o fosos defensivos, documentándose en contadas ocasiones una posterior utilización como lugares de habitación (Ruiz, 1983; Fernández y Ruiz, 1978).

Después de las excavaciones de 1976 en el Cerro de La Cabeza quedó definida una interpretación que ha sido mantenida en siguientes publicaciones. Así pues, los autores proponen globalmente que la finalidad principal de las zanjas se dirige al drenaje de las estructuras de almacenamiento, mientras que los pozos se destinan al abastecimiento de agua (Fernández y Oliva, 1980; Fernández, 1984; Fernández y Oliva, 1985; 1986), con una última utilización conjunta como vertederos. Estimando finalmente que este complejo de estructuras se encuentran vinculadas a una intensa explotación agropecuaria.

En lo que respecta a las estructuras de habitación, las primeras excavaciones documentaron una agrupación de cabañas circulares en La Candeleda y una de planta rectangular en el Cerro Barro (Ruiz, 
1983), así como el reaprovechamiento de algunas zanjas como hábitat en base a la localización de hogares (Ruiz, 1983; Fernández y Ruiz, 1978). En la mencionada excavación del Cerro de La Cabeza se registró una cabaña de planta rectangular con entrada y un cuerpo absidial adosado, estableciendo una separación funcional entre habitación y almacén respectivamente (Fernández y Oliva, 1980; 1986). Por otra parte, uno de los autores considerará a esta cabaña como la única descubierta en el poblado hasta esa fecha (Fernández, 1984). En el año 1985, excavaciones de urgencia localizaron restos de dos cabañas que, a diferencia de las ya citadas, talladas en las margas, presentaban una un muro de adobes y otra de piedras, ubicada esta última en una zanja (Murillo, Pérez, Blanco y Larrey, 1987).

En suma, queda evidenciado que el poblado de Valencina de la Concepción abarca una amplia extensión. Ante esta amplitud territorial y su cronología interna se han planteado para su interpretación algunas posibilidades, como la que sugiere la existencia de grupos de cabañas, pero sin llegar a establecer su interrelación, apreciando pues una "ocupación por zonas" (Ruiz, 1983; Fernández y Ruiz, 1978). Recientemente, J.C. Martín y J.M. Miranda retomarán esta idea, considerando a Valencina como una población que se trasladaba dentro del mismo área a medida que las posibilidades de cultivo se les agotaban y regeneraban, de ahí que estimen diferentes cronologías incluso para una misma estructura (Martín y Miranda, 1988). En un intento de encajar Valencina dentro de una secuencia más amplia, la presentan como heredera tecnológica y cultural de Papa Uvas, siendo sincrónicos ambos yacimientos en los inicios y finales respectivamente.

La situación sobre esta Cornisa resulta óptima para la explotación de una variada gama de recursos, toda vez que éstos hay que verlos hacia el lado contrario del río y alejándose paulatinamente. En efecto, a sus espaldas, fértiles campiñas seguidas de zonas de bosque, hasta enlazar con las vegas de afluentes del Guadalquivir, como el Guadiamar, con evidencias calcolíticas (Burgos, 1991a; 1991b), y la Rivera de Huelva, donde encontrarán aportes alimenticios, así como avituallamientos industriales (líticos, pastas cerámicas, material de construcción). Pero, quizás, más sugerente resulte destacar las posibilidades de desarrollar actividades comerciales. Desde las cañadas en las que se asientan, fácilmente conectarían con otros productos, entre ellos los mineros procedentes del Andévalo a través de Paterna (Escacena, 1983); o de Sierra Morena, a través de la Rivera de Huelva, donde evidencias como el poblado de Castillo de las Guardas (Cabrero y Florido, 1988) y otros aún sin publicar serían nexos de conexión en esta ruta (Murillo, Cruz-Auñón y Hurtado, 1991). Asímismo, enlazarían con otras vías como bien podría ser el cauce del Guadalquivir.

Por su margen derecha, el Guadalquivir transcurre muy cercano a las estribaciones de Sierra Morena y así, los yacimientos se ubican en dos paisajes bien diferentes según se trate de vega o sierra.

Para la VEGA contamos hasta el momento con la excavación en La Morita (Cantillana) (Acosta, Cabrero, Cruz-Auñón, Hurtado, 1987) y de una estructura siliforme de enterramiento en el mismo término, aunque encuadrada por su excavadora en el Bronce Antiguo (Santana, 1991), así como con las referencias en Burguillos (Ponsich, 1974).

En el primer yacimiento se registraron dos niveles de ocupación calcolíticos; documentándose tres fondos de cabañas de tendencia circular y un silo. Resulta sorprendente en este caso la proximidad al río que incluso le lleva a sufrir inundaciones, como demuestra una potente capa de arenas aluviales entre su estratigrafía, indicativo de que soportaron momentos catastróficos.

En este mismo paisaje pero en la actual margen izquierda, otros registros, aportados por la prospección sistemática del término municipal de Tocina, nos informan de restos líticos superficiales que, al presentarse de forma dispersa y escasa, se han interpretado como manifestaciones del "área de captación de recursos o zonas de actividad" relacionadas con los asentamientos conocidos en la zona (Jiménez, Chisvert y Franco, 1990). 
La permanencia en esta zona podría en parte explicarse por los posibles contactos con áreas mineras como Cazalla de la Sierra, a través del río Viar y el Huéznar, o más hacia el este con Constantina, donde al menos para el primer caso tenemos documentada ocupación Calcolítica; cuestión que sería de interés verificar en los registros arqueológicos.

Y cabe así hablar de los asentamientos en el SECTOR CENTRAL DE SIERRA MORENA, donde de momento sólo conocemos hábitats en cuevas, Santiago Chica y Santiago Grande (Pellicer y Acosta, 1982; Acosta, 1986) y las imprecisas referencias de la Cueva de Don Juan en Constantina (Carriazo, 1974) y la Cueva de San Francisco en Guadalcanal (Hernández, Sancho y Collantes, 1955), pero es de suponer una mayor presencia de poblaciones de la Edad del Cobre dada la existencia de sepulturas, caso por ejemplo las de Almadén de la Plata, Guadalcanal, Cazalla de la Sierra y Constantina (Cabrero, 1985a; Salas y Barrionuevo, 1990) o los restos de Alanís de la Sierra (Guerrero, 1987; Larrey y Jiménez, 1990).

En Cazalla de la Sierra, los niveles neolíticos resultan más potentes mientras que en estos momentos disminuyen, de manera que el hecho de mantener o frecuentar estos hábitats debe ser más ampliamente explicado.

Desde la margen izquierda del Guadalquivir y a medida que avanzamos en dirección sur-sureste, la orografía se diversifica ya sea, por los efectos del gran río o de sus más importantes afluentes, generando terrazas, glacis de erosión; o bien, consecuencias y/o evidencias de la amplia historia tectosedimentaria regional. Y es así, como nos encontramos con paisajes que tradicional o genéricamente se denominan vegas, terrazas, alcores y campiña. Hacia el sur aparecen las estribaciones y formaciones de las Cordilleras Béticas, atravesadas ocasionalmente por depresiones intramontanas y las particularidades paisajísticas que ello conlleva.

Abordaremos esta extensa área desde el sur hacia el noreste, alejándonos paulatinamente del gran río, pues en términos generales es así como en la actualidad vemos los más importantes contrastes orográficos, si bien, en ocasiones asoman evidencias de la anteriormente aludida historia geomorfológica meridional.

La COSTA Y CAMPIÑA GADITANA, limitadas globalmente a su izquierda por las tierras que bordean el golfo y a su derecha por las estribaciones de la Sierra Subbética y con ocasionales alineaciones de pequeñas alturas.

El estudio de este sector se debe a trabajos de prospección, como la carta arqueológica de Barbate (Bernabé, 1990), la del Puerto de Santa María (Ruiz Gil, 1987), o los estudios que se vienen realizando en la zona noroccidental de la provincia, centrados por ahora en el término de Jerez de la Frontera y con un mayor detalle en la diversidad de los medios geomorfológicos; así como otras actividades más o menos puntuales o recientes, entre ellas las del Puerto de Santa María o Medina Sidonia.

En la banda costera, la zona de Barbate parece ser que estuvo habitada en el Neolítico, según se adscriben a dicha época algunos talleres líticos localizados muy próximos a la costa. El aumento ocupacional que se registra en la Edad del Cobre se diferencia en dos zonas: la marino-costera y la interior, comprendida entre La Janda y el río Barbate. En la costera ocupan terrazas de poca altitud, mirando al mar, pero provistas de puntos de agua potable y asimismo de tierras cultivables. Igualmente resultan zonas agrícolas las del interior. Según el autor existen marcadas diferencias entre los materiales arqueológicos documentados en ambos paisajes deduciendo que los asentamientos estarían desconectados entre sí, y la explicación podría atender a razones cronológicas o funcionales sin llegar a matizar tales apreciaciones (Bernabé, 1990).

La siguiente información se refiere a los escasos registros en Cádiz (Quintero, 1935; García y Bellido, 1970; Perdigones y Muñoz, 1987; Perdigones, Muñoz y Troya, 1987), y a El Puerto de Santa 
María y contornos, donde zonas próximas a la tradicional necrópolis de Rota (Gener, 1956-1961; Berdichewsky, 1964) han sido objeto de excavaciones recientemente (Perdigones, Muñoz, Blanco y Ruiz, 1987; Ruiz Fernández, 1987; Ruiz Gil y Ruiz Fernández, 1987; Ruiz Fernández y Ruiz Gil, 1989), además de noticias sobre algunos talleres líticos relacionados con asentamientos (Ramos, Giles, Gutiérrez, Mata y Molina, 1989).

En lo que se refiere al yacimiento de La Viña, ubicado en un extenso cerro de poca altitud, tan sólo en la primera publicación se sugiere la posibilidad de fondos de cabañas por la presencia de grandes restos de adobe supuestamente alineados, conformando un muro (Perdigones, Muñoz, Blanco y Ruiz, 1987). Por contra, las estructuras más frecuentes son los silos, algunos de ellos con enterramientos, así como algunas cuevas artificiales, pozos para el depósito de agua y pequeñas zanjas de desagüe. Distinguiendo finalmente un área de hábitat en la zona baja del cerro y un área de almacenamiento en la parte alta, en la que se localizan algunos enterramientos, así como una ocupación temporal de ésta última en función de las arbitrarias conexiones entre algunas estructuras siliformes (Ruiz Fernández y Ruiz Gil, 1989), además de un taller lítico asociado a este poblado (Ramos, 1990).

Respecto a los silos, en unos casos, se considera que mantienen una disposición aleatoria (Perdigones, Muñoz, Blanco y Ruiz, 1987) y en otros se aprecia un agrupamiento en núcleos de tres a seis estructuras, separados entre 20 y 40 metros de otros conjuntos (Ruiz Fernández, 1987; Ruiz Gil y Ruiz Fernández, 1987; Ruiz Fernández y Ruiz Gil, 1989); infiriendo de ello una estructura socioeconómica en la que se detecta una propiedad privada fundamentada en las familias nucleares (Ruiz Fernández, 1987). Sugerente y escueta valoración que debe ser desarrollada no sólo en un marco teórico más sólido, sino también empírico.

Relacionados con este asentamiento se encuentran el yacimiento de El Bercial, a cinco kilómetros, con similares enterramientos en silos, y el yacimiento de Pago de Cantarranas, a un kilómetro (Perdigones, Muñoz, Blanco y Ruiz, 1987). Este último también parece presentar un área de habitación con fondos de cabañas circulares y otra de almacenamiento con numerosos silos (Ruiz Fernández, 1987), así como un importante taller de producción lítica (Ramos, Giles, Gutiérrez, Santiago, Blanes, Mata y Molina, 1989).

En suma, estos asentamientos son interpretados como un gran complejo relacionado fundamentalmente con la explotación de la costa, y en segundo lugar con la campiña al interior a través del arroyo Salado (Ruiz Fernández, 1987; Perdigones, Muñoz, Blanco Ruiz, 1987).

Por otra parte, ciertas diferencias se detectan a la hora de fechar este complejo poblacional. Así, unos lo encuadran en el Calcolítico hasta sus momentos finales (Perdigones, Muñoz, Blanco y Ruiz, 1987), mientras otros establecen sus inicios en el Neolítico Final y un desarrollo durante el Calcolítico Inicial (Ruiz Fernández, 1987), aunque posteriormente se deciden por englobar al yacimiento de La Viña en la primera mitad del tercer milenio (Ruiz Fernández y Ruiz Gil, 1989).

Otras localizaciones costeras han sido aportadas por D. Ruiz Mata (Ruiz, 1986; 1988), destacando el yacimiento de La Dehesa y los niveles iniciales de $D^{a}$ Blanca, con cabañas circulares, zócalos de mampostería adosados a las paredes del fondo excavado y muros de tapial, así como estructuras más pequeñas consideradas como almacenes. O en la Sierra de San Cristóbal, en una altura dominante (Ruiz Gil, 1987). Directamente vinculado con estos asentamientos se halla el pequeño taller de Buenavista, también en la misma sierra (Ramos, Giles, Gutiérrez, Mata y Molina, 1989).

Respecto a la campiña jerezana y áreas cercanas la información hace referencia al antiguo yacimiento de Mesas de Asta (Esteve, 1945; 1950; 1962); y más recientemente al de El Trobal (González, 1987), con silos, algunos de ellos con enterramientos, que recuerdan a los anteriormente mencionados del Puerto de Santa María y Rota, fechado desde el tránsito Neolítico-Calcolítico hasta mediados del 
tercer milenio. Igualmente parece registrarse una cierta tendencia al agrupamiento de estas estructuras. También en este caso se ha localizado un importante taller lítico inmediato al yacimiento (Ramos, Santiago, Molina, Mata, González, Aguilera y Gutiérrez 1989). Se trata de un asentamiento muy extenso que ha sido valorado por su investigadora como una ocupación por zonas, con movimientos internos diacrónicos de la población (González, 1987).

Por otra parte, las investigaciones realizadas recientemente en las diversas áreas geomorfológicas marismas, llanos de Caulina, curso fluvial del río Guadalete...- de esta zona están documentando un intenso poblamiento evidenciado a través de numerosos poblados, a los que se asocian talleres líticos y algunos enterramientos. La ubicación de los asentamientos se caracteriza por una estratégica selección de cerros y pequeñas elevaciones, cuestión que ya ha sido expresada para ocupaciones neolíticas al aire libre con carácter semisedentario y estacional (Ramos, Santiago, Romero, Almagro, Gutiérrez y Mata, 1990). Las primeras estimaciones globales de las complejas relaciones entre talleres, asentamientos, poblados y enterramientos, bajo parámetros conceptuales que consideramos acertados y coherentes, llevan a los autores a valorar un poblamiento, enmarcado en un proceso histórico dialéctico, con unas bases económicas fundamentadas en la explotación intensiva del cereal y en unas estrategias de abastecimientos líticos, producción y distribución en relación con la organización y el control socioeconómico y político del territorio por los centros nucleares, de poblados tipo Mesas de Asta (Ramos, 1990; Ramos, Santiago, Molina, Mata, González, Aguilera y Gutiérrez, 1989; Ramos, Santiago, Gutiérrez y Mata, 1990; Ramos, Santiago, Valverde, Giles, Gutiérrez y Mata, 1990; González y Ramos, 1991).

Por último, cabe señalar el yacimiento de Monte Berrueco (Medina Sidonia) (Escacena, 1985; Escacena y Frutos, 1986), con una estructura de habitación de muros rectos a base de piedras y paredes de tapial, extraña en Andalucía Occidental para estos momentos, por lo que los autores, considerando conjuntamente otros elementos -materiales, inhumaciones individuales-, la atribuyen a un momento de transición.

En la provincia de Sevilla para la ocupación de la margen izquierda del Guadalquivir hasta las estribaciones de la Sierra Sur contamos con una configuración geológica que engloba diferentes unidades:

- TERRAZAS fluviales de formación cuaternaria con pocos puntos de agua y cubierto de bosque en la época a tratar.

- ALCORES, ligeramente de mayor altura, separando las Terrazas de la Vega. Las calcoarenitas que lo componen almacenan gran cantidad de agua que vierten hacia el exterior originando zonas erosionadas - puertos- que facilitan el paso entre la Vega y el Alcor, o hacia las Terrazas. Es de destacar la escasa vegetación, debido a que los vientos han desmantelado el nivel de relleno sobre la roca terciaria.

Los Alcores se encuentra delimitado por los ríos Corbones y Guadaira, que riegan la campiña y se dirigen hacia el Guadalquivir.

- LA VEGA, glacis de erosión con dos elementos decisivos:

a. la distribución irregular de las colinas calizas, compuestas de alberizas pero con la suficiente pendiente para que las aguas corran

b. la vega, suelos impermeables, tierras de bujeo, donde las arcillas sufren alteraciones que impiden el crecimiento de árboles pero posibilitan cultivos estacionales, excepto en los lechos de inundación de los ríos donde no avenan bien las aguas.

- LA CAMPIÑA, prolongación de la Cordobesa, con ocasionales colinas alomadas y amplias vallonadas, hidrológicamente bien dotada por una red no excesivamente caudalosa y con algunas 
fuentes naturales. A causa de sus óptimas condiciones agrícolas, nos encontramos con un espacio muy roturado y transformado por el hombre.

Para estos entornos, varios trabajos de prospección informan sobre la ocupación del territorio en los diferentes paisajes: Alcores (Amores, 1982); Vega del Corbones y Fuentes de Andalucía (Rodríguez, 1984; Fernández, 1987); Campiña sureste (Ruiz, 1985); Ecija (Durán, 1988); así mismo se han realizado otros trabajos similares que al no estar publicados no hemos podido consultar. Junto a ello, actividades puntuales en Sevilla (Fernández y Alonso, 1985); Utrera (Cruz-Auñón y Rivero, 1987a; Santana, 1990); Los Molares (Cabrero, 1987; 1990); y Alcalá de Guadaira (Pellicer y Hurtado, 1987).

En LA CAMPIÑA SEVILLANA, y a continación de los yacimientos que bordean el golfo del Guadalquivir, prácticamente no existe información precisa sobre un poblamiento inmediatamente anterior, es decir Neolítico, a excepción de la indicación de R. Cabrero en el dolmen de Cañada Real (Los Molares) (Cabrero, 1987).

Es por tanto a partir de la Edad del Cobre cuando podemos encontrar una documentación más amplia, y en concreto, a través de la carta arqueológica de M.M. Ruiz Delgado (Ruiz, 1985), con aproximadamente una veintena de ocupaciones. En principio y según el autor, parece que la distribución de los yacimientos no sigue unas normas bien diferenciadas porque el territorio en sí tampoco ofrece importantes relieves. A pesar de esa homogeneidad destaca algunas características físicas que le definen la ubicación de los poblados, como la preferencia por puntos con visibilidad, de gran valor estratégico defensivo, próximos a cruces de cañadas y junto a manantiales o cursos de agua, al menos en los poblados mayores, más estables y de un supuesto desarrollo económico. Con lo que llega a reconocer un "posible esquema de ocupación", fundamentado en el alto índice de densidad de yacimientos, con distancias entre ellos de 3 ó $4 \mathrm{~km}$., densidad sensiblemente superior al de otras zonas Aljarafe, Las Marismas-; en el caso de tres yacimientos que no encajan en este índice alega traslados de población o diferencias cronológicas.

Este esquema de poblamiento queda explicado en base a la potencialidad económica estimada, agricultura y ganadería, directamente relacionada con las posibilidades que ofrece el medio ambiente, especialmente en sus facetas geológicas, edafológicas y climáticas.

Otras investigaciones de carácter más puntual han dado a conocer una serie de ocupaciones como los dos grupos de fondos de cabañas en los contornos del actual casco urbano de Sevilla, donde hoy se ubica la Universidad Laboral, si bien sólo uno de ellos es atribuído a cronologías del III milenio (Fernández y Alonso, 1985). A unos $20 \mathrm{~km}$. aproximadamente, en el término municipal de Utrera, tenemos referencias de estructuras asimiladas a fondos de cabaña (Santana, 1990), o evidencias de enterramientos siliformes como El Junquillo (Cruz-Auñón y Rivero, 1987a). A unos $5 \mathrm{~km}$., en la localidad de Los Molares, los trabajos en el poblado del Amarguillo II han descubierto unas siete estructuras siliformes asignándoles generalmente una funcionalidad de habitación. Para este asentamiento se describen tres "niveles" de ocupación dentro de la misma cultura (Cabrero, 1987; 1990). En nuestra opinión, no queda claro si algunos de estos niveles debe interpretarse como causa de rellenos relativamente contemporáneos, o si realmente responden a ocupaciones continuadas.

Para LOS ALCORES (Amores, 1982) se indica un despoblamiento desde el Paleolítico Inferior, si bien tradicionalmente se señala algún registro Neolítico, concretamente en Campo Real (Bonsor, 1899), cuya entidad cronológica y cultural ha sido cuestionada recientemente (Cruz-Auñón y Jiménez, 1985); será pues en la Edad del Cobre cuando vuelve a ocuparse intensamente. 
Los poblados catalogados, según F. Amores, responden a tres tipos básicos:

- Sobre el Alcor, aprovechando la situación dominante, dejando en segundo plano los condicionamientos que supone la lejanía de los puntos de agua. Este tipo se podría matizar aún más dependiendo que la posición elegida reúna o no condiciones estratégicas. Siendo la zona de mayor densidad poblacional.

- Emplazamientos cara a la Vega, normalmente se sitúan en los "puertos", junto a las vías de aguas freáticas.

- y un tercer tipo detectado es la cueva, aunque solamente contamos con un caso, El Judío.

Respecto a los espacios de habitación, la única documentación se refiere a pellas de adobe que informan sobre el empleo de materiales ligeros para la construcción de parte o totalidad de las estructuras.

En el estudio global de este territorio, el autor plantea "un esquema de equilibrio demográfico", en base a la existencia de un poblado cada 1'6 km., repartiéndose escrupulosamente el territorio de explotación. Distinguiendo ciertos asentamientos con categoría prioritaria, "Centros Nucleares" sobre los que basa este esquema, para los cuales sugiere una continuidad ocupacional durante La Edad del Cobre, y que se encuentran a una distancia de $5 \mathrm{Km}$. justos; mientras que el espacio intermedio estaría poblado por los pequeños asentamientos de vida efímera. Cuando este esquema se rompe-demasiada proximidad entre poblados- se debe a que pertenecen a momentos distintos de la Edad del Cobre, es decir, resuelve el problema sincrónico de densidad por cuestiones de diacronía.

Este esquema tiene su fundamento en su “..visión ecológica de las culturas.." (Amores, 1982 : 47), en la que defiende el carácter determinante del medio y de las posibilidades económicas del mismo como causantes directos de este modelo de distribución ocupacional, por lo que no llega a explicar convenientemente tal distribución "equilibrada-jerarquizada".

No queremos terminar sin hacer mención de un espectacular asentamiento, el Gandul, sobre el que rara vez la investigación ha trabajado de forma sistemática intentando calibrar su importancia ocupacional (Pellicer y Hurtado, 1987), puesto que primordialmente se han venido valorando sus monumentales sepulturas (Leisner, 1943; Cabrero, 1985a). Pensamos que este asentamiento debió ser extremadamente operativo durante el tercer milenio y, en cierto sentido, con un nivel de competitividad y gestión territorial que habrá que contrastar con otros centros de Andalucía Occidental, cuando la cantidad de información nos lo permita.

En la VEGA DEL CORBONES el poblamiento ha sido presentado con una dinámica ocupacional semejante a la de los Alcores, ya que tras las frecuentes evidencias Paleolíticas infero-medias (Fernández, 1990), se abandona y parece no volver a ocuparse hasta el Neolítico, aunque resultan escasos los registros (Rodríguez, 1984), cuando no dudosos (Fernández, 1987). Será por lo tanto para la Edad del Cobre donde I. Rodríguez aprecia un importante aumento de la ocupación y al parecer eligiendo colinas alberizas con manantiales de aguas freáticas, o en las vertientes, evitando siempre los lechos de inundación de los ríos, o las zonas de encharcamiento de la Vega. Sólo en dos casos se sitúan en relieves de poca entidad, pero lo suficiente para amortiguar los efectos negativos. Tales condiciones, por demás, favorecen la visibilidad entre ellos.

En definitiva habla de dos tipos de hábitats:

- una primera línea de asentamientos, más o menos paralela al río, que corresponde a los más pequeños, y a poca distancia entre ellos

- y otra, más alejada del Corbones, coincidiendo con los mayores, Entremalo, El Cerro y El Cerro de San Pedro, a mayor distancia entre sí y con delimitaciones naturales. 
Las explicaciones del autor sobre este poblamiento son abordadas desde dos ópticas: una la relación hombre-medio, y otra la relación hombre-hombre.

Para el primer caso estima como elementos fundamentales que inciden en la distribución de los poblados a los factores económicos, en base a las posibilidades y ofertas del medio: la proximidad a manantiales de agua es determinante en la elección de los asentamientos puesto que esto explica el que haya buenos relieves cercanos al río sin indicios de ocupación, con lo que observa una ausencia de estrategia defensiva en las ubicaciones, la calidad de las tierras de cultivo con aprovechamientos de territorios de explotación complementarios -sílex, caza y/o pastoreo-. Este panorama económico queda definido por el autor como un "modo doméstico de producción".

En el segundo caso, destaca varios factores como la relación proporcional entre el tamaño del asentamiento y el territorio propio de explotación; la visibilidad entre los mismos, así como la existencia de límites naturales con "cierto carácter simbólico de territorialidad". Lo que, en definitiva, le lleva a entender un "modelo de jerarquización" del territorio basándose en la relación Tamaño-Distancia, estableciendo un "modelo de gravedad" donde los pequeños asentamientos sufren un grado de atracción por los mayores.

Encontramos en estas argumentaciones ciertas irregularidades, pues, en primer lugar, no comprendemos por qué define un "modelo de jerarquización" que establece un "modelo de gravedad" entre los asentamientos cuando a su vez nos habla de una "ocupación indiscriminada" del territorio o que los factores económicos (relación hombre-medio) contribuyen a una ocupación anárquica, manifestada en una "..dispersión que aprovecha lugares de mejores recursos, ajeno todo ello a cualquier estrategia.." (Rodríguez, $1984: 301$ ).

En segundo lugar, creemos que la catalogación de la economía como "modo doméstico de producción" no queda suficientemente explicada al plantear una jerarquización poblacional, que entendemos debe manifestar una gestión mayor a nivel de la producción económica y su red-distribución entre los diversos asentamientos y entre zonas próximas.

En nuestra opinión, consideramos que las dos ópticas desde las que aborda el análisis del poblamiento se centran en la relación del hombre con el entorno natural y lo que en sí generan o se materializa en los registros arqueológicos, sin llegar a matizar el verdadero sentido político-social que supone la relación hombre-hombre en su planteamiento del modelo de jerarquización.

Otra información (Fernández, 1987), en parte coincidente con las zonas prospectadas por I. Rodríguez, registra la existencia de dos agrupaciones calcolíticas: una en torno a Los Cerros de San Pedro, al borde del Corbones; y otra, La Loma de la Lombriz, rodeada de fértiles tierras de labor. Se vuelve a remarcar la importancia determinante de las condiciones medio-ambientales en la distribución del poblamiento, entre ellas la elección de zonas cercanas a puntos de aguas freáticas, ubicación en alturas, tierras fértiles, así como la menor importancia de defensibilidad.

Más hacia el noreste, en el término municipal de Ecija, contamos con un trabajo (Durán, 1988), donde queda patente la importante ocupación de la Edad del Cobre, con al parecer una treintena de yacimientos, generalmente asimilados a estructuras siliformes propias de la "Cultura de los Silos" (Collantes, 1969; Carriazo, 1974..); además de evidencias campaniformes. En dicho estudio notamos ciertas insuficiencias de base, lo que nos impide de momento una valoración más efectiva.

Para el PIE DE SIERRA SUBBETICO, partiendo desde la provincia de Cádiz hasta Sevilla, la información la hemos obtenido de algunas cartas arqueológicas, como la de Alcalá de los Gazules (Toscano, 1987a); Montellano (Velasco, Escobar, Oria, Mancebo, Ferrer, García, Rodríguez, Pérez y Sierra, 1990; 1991; Oria, Mancebo, Ferrer, Escobar, García, Rodríguez, Velasco, Sierra, Pérez y Otero, 
1991); Gilena (Romo, Sierra y Vargas, 1991); Osuna (Pérez, Vargas, Romo y Sierra, 1990); Morón de la Frontera (Vera y Fernández, 1991); Estepa (Juárez, 1991); o bien de actividades puntuales como iremos exponiendo al hilo de esta presentación. Tenemos conocimiento de otros estudios o actividades que por no estar publicados no se recogen en esta ocasión.

En términos generales lo que define a este paisaje es el ser una zona de colinas moderadas combinadas con lomas y llanuras, y ocasionalmente algún cerro de fuerte influencia estructural. Litológicamente el predominio es de las variedades de margas, ya sean calizas, calcáreas, arenosas, arcillosas, silíceas, en sus diferentes combinaciones (Rosa y Moreira, 1987).

En definitiva, viene a ser ese límite entre el paisaje de campiña y el de sierra donde se generan biogeográficamente ecotonos que, circunstancialmente, continuarán a través de las depresiones intramontanas en dirección sur-sureste. Por lo que, las posibilidades de utilización del paisaje a nivel de subsuelo y suelo resultan óptimas, toda vez que de gran variedad. A ello habría que unir la posible utilización de las vías naturales de paso, a través de las citadas depresiones, que conectarían con el sudeste.

En ningún caso hemos podido recoger información clara sobre poblamientos anteriores, lo cual nos impide calibrar de momento la antigüedad del proceso dialéctico histórico en esta zona.

Para la provincia de Cádiz, el extremo más meridional, tenemos noticias de ocupaciones en Arcos de la Frontera; Sierra de Gibalbín; y Alcalá de los Gazules (Toscano, 1987a), al parecer con un docena de asentamientos, tanto al aire libre como en cuevas. Pero como apuntamos anteriormente, la mayoría de la información permanece inédita lo que nos dificulta valoraciones concretas sobre este paisaje que debió estar bien poblado a juzgar por la frecuente localización de necrópolis (Corzo, 1983; Cabrero, 1985a) y más recientemente de talleres líticos en los términos de Arcos, Bornos y Villamartín (Ramos, 1990), como ejemplifica el gran taller de Fuensanta (Arcos) (Ramos, Santiago, Molina, Mata y Gutiérrez, 1989), con probabilidad de tener asociados varios fondos de cabañas y relacionado con el poblamiento de las áreas cercanas (Ramos, Santiago, Molina, Mata, González, Aguilera y Gutiérrez, 1989; Perdigones, Molina y Rojo, 1987).

En la provincia de Sevilla, las investigaciones en la zona de Montellano (Velasco, Escobar, Oria, Mancebo, Ferrer, García, Rodríguez, Pérez y Sierra, 1990; 1991; Oria, Mancebo, Ferrer, Escobar, García, Rodríguez, Velasco, Sierra, Pérez y Otero, 1991) parten también de considerar el medio físico como elemento determinante para el desarrollo de las poblaciones humanas a lo largo de su evolución histórica, donde el factor de una economía supuesta adquiere un rango predominante en sus argumentaciones. Así, los autores diferencian dos tipos de asentamientos dispersos: Campiña y Sierra. En la Campiña los asentamientos aparecen próximos entre sí, sobre pequeñas lomas aisladas cercanas a puntos de agua, y en la actualidad tierras de labor, y se interpretan como ubicaciones de predominante valor económico, entendiendo dicho valor como agrícola. En la Sierra se localizan hallazgos sueltos de material lítico en alturas medias, en zonas de pendiente y suelos pedregosos, así como en la cuenca del Guadalete, y a mayor distancia entre ellos; en base a esto han sido considerados lugares exclusivamente de trabajo lítico y sin posibilidades de cultivo. No se han localizado asentamientos con entidad de poblados ni enterramientos por lo que consideran los asentamientos como lugares de producción y, en definitiva, se opta por asemejar esta característica ocupación dispersa, cercana a puntos de agua, con otras zonas, los Alcores y la Campiña sevillana. Asímismo, plantean una "red de interrelaciones", al parecer económica, sin especificar nada más al respecto.

Por contra, en el término municipal contiguo, Morón de la Frontera (Vera y Fernández, 1991), se comprueban yacimientos ligados a la campiña sensiblemente diferentes a pesar de su proximidad. Tal es el caso, por ejemplo, del Cerro de Santiesteban, de gran visibilidad y por encima de los $450 \mathrm{~m}$. de 
altitud, con visos de haber sido un importante asentamiento dedicado a la explotación cerealista; mientras que en altitudes que difícilmente superan los $200 \mathrm{~m}$., e igualmente mirando hacia la campiña, otras evidencias con industrias líticas, o registros de silos (Carriazo, 1966; 1974) comparten un mismo paisaje. Hacia la zona de sierra la información básicamente se refiere a enterramientos (Cabrero, 1985a; Gil, Jiménez, Oliva y Puya, 1985; Salas y Barrionuevo, 1990; Cruz-Auñón y Rivero, 1991) y talleres líticos. Respecto a los primeros, una reciente interpretación (Vera y Fernández, 1991), especialmente de cuatro importantes grupos dolménicos, los valora como "marcadores territoriales" en función de la ausencia de poblados asociados y de su disposición lineal en tradicionales rutas ganaderas y comerciales, siguiendo la tesis C. Renfrew (Renfrew, 1976). Teniendo en cuenta el alto grado de parcialidad de la información disponible para la zona, esta valoración no se nos presenta muy factible y necesita de una mejor documentación empírica.

En el término municipal de Osuna, tan sólo se hace referencia a tres yacimientos, en campiña, y con pocos registros, de manera que los investigadores encuentran dificultades para definir fases culturales concretas (Pérez, Vargas, Romo y Sierra, 1990).

La información del término municipal de Estepa presenta las mismas características, es decir, una decena de localizaciones dispersas y escasas, en su mayoría de materiales líticos (Hernández, Sancho y Collantes, 1955; Juárez, 1991).

Para la zona de Gilena, la documentación existente (Moreno y Contreras, 1981; Romo, Sierra y Vargas, 1991) y las sucesivas actividades que nosotros mismos venimos realizando (Cruz-Auñón y Rivero, 1987c; 1987b, 1990; Cruz-Auñón, Moreno y Cáceres, 1989; 1990; Moreno y Cáceres, 1991), nos están permitiendo una evaluación del comportamiento local.

Se han excavado diversos tipos de estructuras de las que destacamos la presencia de habitaciones mayores, talladas en el subsuelo hasta aproximadamente $2 \mathrm{~m}$. de profundidad, junto a otras de menor entidad y dimensiones. Las restantes estructuras responden a actividades diferentes, como las sepulturas en Cuevas Artificiales. La analítica sobre el territorio y sobre los registros nos está llevando a reconocer como novedad una explotación de adehesamientos donde mantienen una ganadería no estabulada. Además, la proximidad a canteras les permite el acceso a otros productos demandables.

Estos pequeños asentamientos, abundantes y sumamente dispersos por el Bajo Valle del Guadalquivir, posiblemente nos ayuden a entender otras ocupaciones más o menos próximas y de más difícil recuperación por lo avanzado de su destrucción, caso de Marinaleda en particular (Romero, 1990), así como la tradicionalmente llamada "Cultura de los Silos" en general (Collantes, 1969; Carriazo, 1974).

Por último vamos a tratar la SIERRA, paisaje que en la provincia de Cádiz ocupa mayor territorio, si bien para Sevilla el límite jurisdiccional excluye las grandes elevaciones.

En Cádiz la información está centrada en zonas más o menos concretas como el inventario de la Sierra de Grazalema (Toscano, 1987b); la carta arqueológica de Benaocaz, (Guerrero, 1990); junto a otra inédita de L. Perdigones en Arcos de la Frontera, así como actividades arqueológicas que iremos citando.

Durante el Neolítico este sector estuvo bien poblado ocupando espacios de cuevas y al aire libre (Mora, 1970; 1979; 1980; Giles, 1979; Pellicer y Acosta, 1982; Santiago, 1983; Acosta, 1986; Acosta y Pellicer, 1990; Guerrero, 1990; Ramos, Santiago, Gutiérrez y Mata, 1990; Martínez y Pereda, 1991), mientras que se asiste a un descenso ocupacional en la Edad del Cobre. En el caso de Benaocaz, frente a los 17 yacimientos neolíticos tan sólo se catalogan 6 calcolíticos de los que sólo dos, Mezquitilla y el Peñón Gordo (Perdigones y Guerrero, 1987) documentan estructuras: un posible fondo de cabaña y una zanja respectivamente. El resto de los yacimientos aportan industrias líticas y excepcionalmente dos 
vasos en la Sima de las Vasijas. Este poblamiento se interpreta en base a la predominante elección de lugares estratégicos, aunque no alcanzamos a entender en qué sentido; y en la actividad prospectora de la explotación del silex (Guerrero, 1990).

Las excavaciones en las cuevas de Dehesilla y Parralejo, con niveles Calcolíticos, testimonian una menor frecuencia de la ocupación dada la potencia de los mismos (Pellicer y Acosta, 1982; Acosta 1986; Acosta y Pellicer, 1990).

En la provincia de Sevilla se podría asimilar a ocupación en sierra algunos de los yacimientos mecionados para Montellano o Morón de la Frontera, pero al estar muy en relación con paisajes de pequeñas vegas pueden plantear el problema de adscripción convencional a piedemonte o Sierra. Unicamente conocemos un yacimiento en cueva, San Doroteo de Algámitas (Pellicer, 1986) con materiales neolíticos, y que podría documentar una continuidad poblacional calcolítica entre sus niveles, pero no parece tener posibilidades de excavación.

El hecho de que se siga manteniendo o frecuentando este tipo de hábitat, entre otro orden de cosas, puede estar en relación con actividades temporales de tipo ganadero, sobre las que documentarían los análisis faunísticos, además de las señaladas para la explotación del silex (Ramos, 1990). No obstante, notamos una carencia de estudios para estos paisajes de sierra.

De toda esta información queremos destacar en primer lugar la labor de D. M. Pellicer al programar una investigación encauzada a conocer mejor el antiguo poblamiento de Andalucía Occidental. Bajo su dirección se han realizado aproximadamente unas doce cartas arqueológicas que, con mucho hoy, vienen a suponer la más amplia fuente de información al respecto y donde se patentiza la intencionalidad de unos objetivos bien definidos, toda vez que cada investigador aportó de forma sensiblemente diferente, sugerentes valoraciones sobre el análisis del territorio estudiado.

De una primera observación de los registros ocupacionales calcolíticos sobre la cartografía, notamos dos situaciones bien distintas al contrastarlo con los momentos anteriores:

A. Poblaciones que siguen manteniendo o frecuentando su tradicional medio, como ocurre generalmente en el caso de los hábitats en cuevas. Así tenemos en el bloque Occidental de Sierra Morena: la Cueva de la Mora (Jabugo), de confirmarse su ocupación como asentamiento; en el sector Central: las cuevas de Cazalla; y en la Sierra Subbética: las cuevas de Cádiz.

En tales casos no se advierte un aumento en la expansión poblacional, sino simplemente un estancamiento, cuando no un retroceso. También es verdad, que es precisamente en estos ambientes de sierra donde menos prospecciones se han realizado y más dificultades conlleva la actual localización de asentamientos.

Generalmente las explicaciones a estas ocupaciones giran en torno a la continuidad de unas tradiciones culturales locales o muy próximas.

En este medio, se pueden mantener bases económicas neolíticas, pero igualmente se cuenta con la opción de añadir la explotación de algún producto o recurso, metalúrgico, lítico, agropecuario, etc.., participando así en un tipo de relación socio-económica más compleja, propia de la Edad del Cobre. Puede ocurrir que se trate de ocupaciones temporales para el mantenimiento de algún recurso, de ahí ese aspecto de baja densidad.

Otra situación alude a poblaciones que se trasladan dentro de su mismo medio, según se ha señalado para gran parte del poblamiento onubense (Múrtiga y Chanza, Andévalo, estuario Tinto y Odiel, y litoral). 
En estas circunstancias parece asistirse a un relativo aumento de la dispersión poblacional a la vista del incremento de yacimientos registrados. No obstante, hay autores que señalan que el patrón de asentamiento en zonas concretas, caso del Andévalo, es semejante al inmediatamente anterior y que incluso se observa una concentración poblacional.

Con estos hábitats parece quizás que pretendan incrementar el territorio de explotación de recursos, o bien controlar la salida de productos, dado que se viene enfatizando en "ubicaciones estratégicas" (visibilidad, defensibilidad, zonas agrícolas); falta por tanto calibrar la dimensión de dicha estrategia económica, así como la entidad diacrónica o sincrónica de estos movimientos y sus resultados.

B. Poblaciones en un nuevo medio. El hombre va a ocupar zonas que prácticamente estaban vacías desde el Paleolítico, y donde las referencias a poblamientos neolíticos resultan de momento escasas cuando no poco claras.

Este sería el caso de los asentamientos a lo largo del Guadalquivir y los marcos geográficos del contorno con su variabilidad morfológica y ecológica.

La cantidad de yacimientos registrados, en ocasiones a distancias medias entre 1'6 km. (Los Alcores), $4 \mathrm{~km}$. (La Campiña), viene dando lugar a núcleos poblacionales más o menos mayores pero concentrados de aspecto "urbano" y en otros casos a núcleos dispersos de aspecto "rural" (pie de sierra), además de las pocas ocupaciones en cuevas.

Para explicar esta expresión poblacional se suelen manejar varias razones que cobran mayor o menor énfasis según se conceptualicen a través de algún parámetro teórico. Así pues, se alude:

1.. Al aspecto o cualidad geográfica. Frecuentemente vemos manejar la expresión "...ubicación en zonas favorables para el establecimiento del asentamiento en sí (alturas medias, cabezos, zonas alberizas...), huyendo del lecho de inundación de los ríos...", llevándolo al extremo de "...circunstancia que incluso minimiza sus condiciones estratégicas...".

Aunque en realidad apreciamos ocupaciones del Cobre en cualquier tipo de paisaje, y no sólo eso, estas poblaciones son susceptibles de transformar y crear paisajes nuevos.

2.․ Las razones más explotadas giran en torno a las posibilidades y recursos del medio, especialmente en las agrícolas, y en ocasiones como única causa de la mayoría de las ubicaciones, llegándose a plantear cuestiones como a "mayor rentabilidad mayor densidad"; así cuando varios núcleos resultan excesivamente próximos, en relación con el territorio de explotación, necesariamente se ven forzados sus interpretes a aludir a razones de diacronías.

Y más inocentes aún nos resultan las propuestas que generosamente asocian potencialidad de recursos a potencialidad económica partiendo de datos actuales y sin una comprobación empírica, caso de muchas de las cartas arqueológicas.

En este sentido, nos parece oportuno recordar como la presencia de una materia prima, recurso o producto, dentro de un núcleo poblacional (marfil, metal, incluso cereal...) necesariamente no implica que sea dicho colectivo quién lo explote o procese, máxime en estas comunidades con una organización de espacios económicos diferenciados y de actividades comerciales.

3.․ Por último hemos de mencionar los intentos de explicar esta expresión poblacional en base a las relaciones hombre-hombre y hombre-medio. Así entre las pocas propuestas, quizás la más sugerente resulta la de los Alcores, abordando desde una perspectiva funcional y temporal la estructura ocupacional del espacio. Si bien no quedan suficientemente explicadas las causas que motivan el diseño de tal estructura, la competitividad entre los llamados "Centros Nucleares" y finalmente su inoperancia, ya que la razones "ecológicas" sin comprobaciones empíricas pueden llevarnos simplemente a suposiciones. 
Cuando se ha intentado explicar abiertamente el diseño "jerárquico" en la ocupación del territorio, y de modo sincrónico, frecuentemente encontramos contradicciones en cuanto a la interpretación de la operatividad política, caso del Corbones con un "modelo de jerarquización" explicado, en definitiva, como "..una dispersión que aprovecha lugares de mejores recursos, ajeno todo ello a cualquier estrategia..”; o para el Andévalo donde tras plantear una jerarquización, posteriormente se opta por una indefinida "...diferenciación -que no jerarquización- social...". Quizás la dificultad estriba en un mejor conocimiento de la base socio-económica sobre las que han de plantear tales conjeturas.

En definitiva, notamos que esta manifestación del incremento de yacimientos en Andalucía Occidental, necesita ser explicada a partir de otras lecturas sobre los registros y, como no, a través de otros planteamientos teóricos que, por una parte, intenten reconocer la articulación verticalizada de estos asentamientos en el tiempo y en el espacio; y por otra, la casuística del proceso histórico donde se generaron y basaron tales circunstancias y como, en momentos inmediatamente anteriores y posteriores, se asiste a expresiones diferentes. Labor que pensamos abordar en un futuro trabajo.

Las propuestas metodológicas con las que se vienen estudiando otros sectores de la región, caso de la Alta Campiña del Guadalquivir o Sudeste, pueden servir, a la luz de sus resultados, de opciones y modelos contrastables para abordar la investigación de este ámbito geográfico.

\section{BIBLIOGRAFIA}

ACOSTA, P. (1986): "El Neolítico en Andalucía Occidental: Estado Actual" Homenaje a L. Siret. (Cuevas del Almanzora, 1984). Sevilla : 136-151.

ACOSTA, P., CABRERO, R., CRUZ-AUÑON, R., HURTADO, V.

(1987): "Informe preliminar sobre las excavaciones de La Morita (Cantillana, Sevilla). 1985". Anuario Arqueológico de Andalucía. 1985 II : 150-152.

ACOSTA, P., PELLICER, M. (1990): La Cueva de la Dehesilla (Jerez de la Frontera). Jerez de la Frontera.

AMO, M. del. (1976): "Restos Paleolíticos y Neolíticos en la Provincia de Huelva". Huelva Arqueológica II : 191-196.

AMORES, F. (1982): Carta Arqueológica de los Alcores (Sevilla). Sevilla.

BELEN, M.". (1991): "Apuntes para una Historia de la Arqueología Andaluza: Francisco M. Tubino (18331888)". Boletín del Museo Arqueológico Nacional IX n.ำ 1 y $2: 7-15$.

BERDICHEWSKY, B. (1964): "Los Enterramientos en Cuevas Artificiales del Bronce I Hispánico". Biblioteca Praehistorica Hispana VI Madrid.

BERNABE, A. (1990): "Memoria de las Prospecciones Arqueológicas Superficiales realizadas en Barbate en el año 1987". Anuario Arqueológico de Andalucía 1987 II : 19-21.

BONSOR, G. (1899): "Les Colonies Agricoles Preromaines de la Vallée du Betis". Revue Archéologique 3" Serie XXXV. París.

BORJA, F., GOMEZ, F. (1991): "Yacimientos en travertinos: los casos de Alajar y Zufre en la Sierra de Huelva (Prospección Geoarqueológica, 1988)". Anuario Arqueológico de Andalucía 1988 III : 133-138.

BUERO, M." S., GUERRERO, L.J., IGLESIAS,E., VENTURA, J.J. (1978): "Yacimiento del Bronce en Santa Eufemia". Archivo Hispalense 186 : 59-65.

BURGOS, A.R. de (1991a): "Prospecciones arqueológicas en la Cuenca Media del Río Guadiamar y Cuenca del Arroyo Ardanchón: Ocupación territorial, fuentes y recursos, tecnología lítica..". II Congreso de Historia de Andalucía, (en prensa).

(1991b): Prospecciones Arqueológicas en el Aljarafe Occidental y Campo de Tejada: El Calcolítico Precampaniforme. Sevilla.

CABRERO, R. (1985a): "Tipología de los Sepulcros Calcolíticos en Andalucía Occidental". Huelva Arqueológica VII : 207-263. 
(1985b): “El sepulcro megalítico de Caño Ronco (Camas, Sevilla) y su vinculación con el yacimiento calcolítico de Valencina de la Concepción". Prehistoria I : 1-16.

(1986): "El Megalitismo en la Provincia de Huelva I: Aportaciones de nuevos datos y estudios de la Arquitectura". Huelva en su Historia 1 : 83-147.

(1987): "Informe preliminar sobre las excavaciones arqueológicas realizadas en el yacimiento de Amarguillo II (Los Molares). Sevilla". Anuario Arqueológico de Andalucía 1986 II : 180-185.

(1990): "El poblado de la Edad del Cobre denominado Amarguillo II (Los Molares, Sevilla). Informe preliminar tras la excavación sistemática de 1987”. Anuario Arqueológico de Andalucía 1987 II : 276-277.

CABRERO, R., FLORIDO, C. (1988): "Un importante enclave arqueológico de la Edad del Bronce situado en el Término Municipal del Castillo de las Guardas (Sevilla): Tumbas megalíticas y Poblado". I Congreso Nacional Cuenca Minera de RíoTinto. (RíoTinto, Huelva) : 1-18.

CAMALICH, M. ${ }^{a}$ D., MARTIN, D., ARCO, M. ${ }^{a}$ C del (1984): "Aproximación al estudio de la cerámica neolítica y eneolítica de la Provincia de Huelva". Tabona : 93-216.

CARO, A. (1982): "Notas sobre el Calcolítico y el Bronce en el borde de las marismas de la margen izquierda del Guadalquivir". Gades $9:$ 71-90.

(1985): “Aproximación a la Arqueología del Bajo Guadalquivir: Las Marismas”. El Río. El Bajo Guadalquivir : 74-77.

(1991): Lebrija. La ciudad y su entorno, 1. (Prehistoria y Protohistoria). Colección: Conoce Lebrija n. 2.

CARO, A., ACOSTA, P., ESCACENA, J.L. (1987): "Informe sobre la prospección arqueológica con sondeo estratigráfico en el solar de la calle Alcazába (Lebrija, Sevilla)". Anuario Arqueológico de Andalucía 1986. II: 169-174.

CARRIAZO, J. de M. (1961-1962): "El Dolmen de Ontiveros (Valencina de la Concepción, Sevilla)". Homenaje al Profesor Cayetano de Mergelina. (Murcia, 1961) : 209-229.

(1966): "Memoria de los trabajos de excavación y hallazgos arqueológicos realizados en la zona de Sevilla durante el año 1965". Noticiario Arqueológico Hispánico VIII-IX. 1964-1965 : 301-312.

(1973): Tartessos y "El Carambolo". Investigación arqueológica sobre la protohistoria de la Baja Andalucía. Madrid.

(1974): Protohistoria de Sevilla. Sevilla.

CASTIÑEIRA, J., CASTIÑEIRA, R., RAMOS, J., VALLESPI, E. (1988): “Talleres líticos del Calcolítico y Edad del Bronce en la cuenca minera de Río Tinto y su relación con la minería prehistórica. El ejemplo de La Chaparrita (Nerva, Huelva)".I Congreso Nacional de la Cuenca Minera de RíoTinto. (RíoTinto, Huelva) : 37 72.

COLLANTES, F. (1969): "El Dolmen de Matarrubilla". V Symposium Internacional de Prehistoria Peninsular (Jerez de la Frontera, 1968) : 47-67.

CORZO, R. (1983): "Necrópolis de la edad del Bronce en Las Valderas (Arcos)". Catálogo de Bellas Artes 83 : 12. Ministerio de Cultura. Madrid.'

CRUZ-AUÑON, R., JIMENEZ, J.C. (1985): "Historia crítica del antiguo yacimiento de Campo Real (Carmona)". Habis $16: 417-452$.

CRUZ-AUÑON, R., RIVERO, E. (1987a): "Sepultura Calcolítica del Junquillo (Utrera, Sevilla). Excavación de urgencia en 1985". Anuario Arqueológico de Andalucía 1985 III : 277-278.

(1987b): "Prospección con sondeos en el yacimiento prehistórico de El Negrón (Sevilla)". Anuario Arqueológico de Andalucía 1986 II : 175-179.

(1987c): Gilena, un foco de especial interés para el estudio de la Edad.del Cobre en Andalucía. Gilena (Sevilla).

(1990): "Yacimiento del Negrón (Gilena, Sevilla). Campaña 1987”. Anuario Arqueológico de Andalucía 1987 II : 278-280.

(1991): "Necrópolis de Cuevas Artificiales en Montegil (Morón de la Frontera, Sevilla)". Anuario Arqueológico de Andalucía 1988 III : 279-282.

CRUZ-AUÑON, R., MORENO, E., CACERES, P. (1989): “Campaña de 1989 en el yacimiento del Negrón (Gilena, Sevilla)". Anuario Arqueológico de Andalucía 1989 II (En prensa). 
(1990): "Estudio de materiales en el yacimiento del Negrón (Gilena, Sevilla)". Anuario Arqueológico de Andalucía 1990 II (En prensa).

DIAZ, F. (1987): "El relieve de Andalucía". Cano, G. (dir.): Geografía de Andalucía II : 11-98.

DURAN, V. (1988): "Carta Arqueológica del Término Municipal de Ecija". Actas I Congreso sobre Historia de Ecija I (Ecija, Sevilla. 1986) : 9-32.

ESCACENA, J.L. (1983): "Problemas en torno a los orígenes del urbanismo a orillas del Guadalquivir". Gades $11: 39-83$.

(1985): "El «Monte Berrueco» de Medina Sidonia (Cádiz): un modelo de transición del Calcolítico al Bronce en Andalucía Occidental". Gades $13: 69-101$

(1987a): "Excavación en La Marismilla (Puebla del Río, Sevilla). 1984". Anuario Arqueológico de Andalucía 1985 III : 296-298.

(1987b): "Informe sobre las excavaciones arqueológicas en el yacimiento de La Marismilla (Puebla del Río, Sevilla)" Anuario Arqueológico de Andalucía 1985 II : 241-262.

ESCACENA, J.L., FRUTOS, G. de (1986): "El Tránsito del Calcolítico al Bronce a través del «Monte Berrueco» de Medina Sidonia (Cádiz)". Trabajos de Prehistoria 43 : 61-84.

ESCACENA, J.L., LAZARICH, M. (1985): "Nuevos datos para una valoración del componente africano en las culturas neolíticas de la vertiente atlántica meridional de la Península Ibérica". Anales de la Universidad de Cádiz II : 25-82.

ESCACENA, J.L., RODRIGUEZ, M. (1988): “La Marismilla: ¿Una salina neolítica en el Bajo Guadalquivir?”. Revista de Arqueología 89 : 15-24.

ESCACENA, J.L., RODRIGUEZ, M., ALONSO, M.C. (1990): "La Marismilla. Una salina prehistórica en el sur de España". II Congreso Internacional del Estrecho de Gibraltar. Ceuta. (En prensa).

ESTEVE, M. (1945): "Excavaciones de Asta Regia (Mesas de Asta, Jerez)". Acta Arqueológica Hispánica III. Madrid.

(1950): "Excavaciones de Asta Regia (Mesas de Asta, Jerez). Campaña de 1945-46". Informes y Memorias de la Comisaría General de Excavaciones Arqueológicas n.. 22.

(1962): "Excavaciones de Asta Regia (Mesas de Asta, Jerez). Campaña de 1949-50 y 1955-56". Centro de Estudios Históricos Jerezanos n.o 19 : 11-37.

FERNANDEZ, J.J. (1987): "Avance sobre la Carta Arqueológica de la Comarca de Fuentes de Andalucía (Sevilla). 1985”. Anuario Arqueológico de Andalucia 1985 II : 109-114.

(1990): "Prospección Arqueológica Superficial de los ríos Corbones y Guadaira. Campaña 1987". Anuario Arqueológico de Andalucía 1987 II : 161-163.

FERNANDEZ, F. (1984): “Las Edades del Metal”. Sevilla y su Provincia I-II. Sevilla : 35-49.

FERNANDEZ, F., ALONSO, J. (1985): "Un fondo de cabaña campaniforme en la Universidad Laboral de Sevilla”. Noticiario Arqueológico Hispánico 22 : 9-26.

FERNANDEZ, F., OLIVA, D. (1980): "Los ídolos calcolíticos del Cerro de la Cabeza (Valencina de la Concepción, Sevilla)". Madrider Mitteilungen $21: 20-44$.

(1985): "Excavaciones en el yacimiento calcolítico de Valencina de la Concepción (Sevilla). El corte C («La Perrera»)". Noticiario Arqueológico Hispánico 25 : 9-131.

(1986): "Valencina de la Concepción (Sevilla). Excavación de urgencia". Revista de Arqueología 58 : 19-33.

FERNANDEZ, F., RUIZ, D. (1978): "El «Tholos» del Cerro de la Cabeza, en Valencina de la Concepción (Sevilla)". Trabajos de Prehistoria 35 : 148-224.

FERNANDEZ, J. (1982): "El yacimiento metalúrgico de San Bartolomé de Almonte". Revista Huelva. 4 : 40-46. (1983): "San Bartolomé de Almonte: yacimiento metalúrgico de época tartésica". Revista de Arqueología 26 : 24-33.

(1986): "Economía tartésica: Minería y metalurgia”. Huelva en su Historia. 1 : 149-170.

GARCIA Y BELLIDO, A. (1970): “Algunas novedades sobre la Arqueología púnico-tartessia”. Archivo Español de Arqueología 43 : 3-6.

GARRIDO, J.P. (1971): "Los poblados del Bronce I Hispánico del Estuario del Tinto-Odiel y la secuencia cultural megalítica de la región de Huelva". Trabajos de Prehistoria 28 : 93-118. 
GENER, E. (1956-1961): "Memoria sobre las excavaciones hechas en los terrenos de la Base Naval de Rota". Noticiario Arqueológico Hispánico 5 : 183-192.

GIL, M. …, JIMENEZ, J.C., OLIVA, D., PUYA, M. (1985): “El sepulcro de galería de «El Hoyo del Gigante» (Morón de la Frontera, Sevilla)". Huelva Arqueológica VII : 265-292.

GILES, F. (1979): "Cueva del Higueral (Arcos de la Frontera)". Arqueología 1979 : 70.

GONZALEZ, R. (1987): "El yacimiento de «El Trobal» (Jerez de la Frontera, Cádiz). Nuevas aportaciones a la cultura de los silos de la Baja Andalucía". Anuario Arqueológico de Andalucía 1986 III : 82-88.

GONZALEZ, R., RAMOS, J. (1991): “Torre Melgarejo, un sepulcro de inhumación colectiva en los Llanos de Caulina (Jerez, Cádiz)”. Anuario Arqueológico de Andalucía 1988 III : 84-98.

GUERRERO, L.J. (1987): "La necropólis del Pago de San Ambrosio de Alanís de la Sierra. Sevilla: 1" Campaña de urgencia". Anuario Arqueológico de Andalucía 1986 III : 343-350.

(1990): "Carta Arqueológica de Benaocaz (Cádiz): Inicio a la Sistematización Arqueológica de la serranía gaditana”. Anuario Arqueológico de Andalucía 1987 II : 354-366.

HERNANDEZ, J., SANCHO, A., COLLANTES, F. (1955): Catálogo Arqueológico y Artístico de la Provincia de Sevilla. Tomo IV. Sevilla.

HUNT, M.A. (1991): "Prospección Arqueológica Superficial en la Provincia de Sevilla”. Anuario Arqueológico de Andalucía 1988 III : 286-291.

JIMENEZ, J.C., CHISVERT, N., FRANCO, C. (1990): "Fuentes Arqueológicas para el estudio de la historia local de Tocina". Tocina. Estudios Locales 2 : 9-52.

JUAREZ, J.M. (1991): "Prospección Arqueológica Superficial del Término Municipal de Estepa (Sevilla)". Anuario Arqueológico de Andalucía 1988 III : 340-344.

LARREY, E., JIMENEZ, J.C. (1990): "Excavación de urgencia en el "Pago de San Ambrosio» Alanís de la Sierra (Sevilla). Campaña 1987". Anuario Arqueológico de Andalucía 1987 III : 612-617.

LAVADO, M.' L. (1990): "Carta Arqueológica de la margen izquierda de la desembocadura del Guadalquivir: Sanlúcar (Norte) y Trebujena”. Anuario Arqueológico de Andalucía 1987 III : 126-133.

LEISNER, G. Y V. (1943): Die Megalithgräber der Iberischen Halbinsel. Erster Teil: Der Süden. RömischGermanische Forshungen 17. Berlín.

MARTIN, J.C. (1985): "Papa Uvas. I. Aljaraque. Huelva. Campañas de 1976 a 1979”. Excavaciones Arqueológicas en España 136.

(1986a): "Aproximación a la secuencia del hábitat en Papa Uvas (Aljaraque, Huelva)". Homenaje a L. Siret. (Cuevas del Almanzora, 1984). Sevilla : 227-242.

(1986b): "Papa Uvas. II. Aljaraque. Huelva. Campañas de 1981 a 1983". Excavaciones Arqueológicas en España 149.

(1987): "Memoria de los trabajos realizados en el yacimiento de Papa Uvas (Aljaraque, Huelva)". Anuario Arqueológico de Andalucía 1986 II : 311-316.

MARTIN, J.C., GOMEZ, M.J., ALVAREZ, M.T., CHAVES, P. (1985): "Nueva interpretación sobre los poblados en el estuario del Tinto-Odiel, Huelva" Huelva Arqueológica VII : 161-206.

MARTIN, J.C., GOMEZ, M.J., CONSUEGRA, S. (1990a): "Informe de los trabajos realizados en Papa Uvas durante la campaña de 1987. (Aljaraque, Huelva)". Anuario Arqueológico de Andalucía 1987 II : $246-251$. (1990b): "Urgencia en Aljaraque, Huelva". Anuario Arqueologico de Andalucía 1987 III : 314-316.

MARTIN, J.C., MIRANDA, J.M. (1988): "El poblado calcolítico de Valencina de la Concepción (Sevilla): una revisión crítica". Cuadernos de Prehistoria y Arqueología de la Universidad Autónoma de Madrid. 15 : 3767.

MARTINEZ, F., PEREDA, C. (1991): “La necrópolis prehistórica del Cerro de la Casería, Alcalá del Valle (Cádiz)". Anuario Arqueológico de Andalucía 1988 III : 78-83.

MENENDEZ-AMOR, J., FLORSCHUTZ, F. (1973): "Resultados del análisis paleobotánico de una capa de turba en las cercanías de Huelva (Andalucía)". Estudios Geológicos XX n.․ 3 y 4.

MORA, L. (1970): "El yacimiento prehistórico de la Cueva de Picado (Cádiz)". Trabajos de Prehistoria 27 : 279-286.

(1979): "Cueva de las Palomas (Jerez de la Frontera)". Arqueología 1979 : 71. 
(1980): “Cueva de las Palomas (Jerez de la Frontera)". Arqueología 1980 : 61.

MORENO, E., CACERES, P. (1991): "Prospecciones geofísicas en el yacimiento «El Negrón» (Gilena, Sevilla)". IV Jornadas de Arqueofísica y Teledetección Aplicadas a la Arqueología. (Palos de la Frontera, Huelva. 1991). (En prensa).

MORENO, M.” A., CONTRERAS, F. (1981): "Un yacimiento de la Edad del Cobre en Gilena (Sevilla)". Cuadernos de Prehistoria de la Universidad de Granada 5 : 181-200.

MURILLO, T., CRUZ-AUÑON, R., HURTADO, V. (1991): "Excavaciones de urgencia en el yacimiento calcolítico de Valencina de la Concepción (Sevilla)". Anuario Arqueológico de Andalucía 1988 III : 354-359.

MURILlO, T., PEREZ, C., BLANCO, A., LARREY, E. (1987): "Excavación en el yacimiento calcolítico del Polideportivo de Valencina de la Concepción (Sevilla). 1985". Anuario Arqueológico de Andalucía 1985 III : 311-315.

OBERMAIER, H. (1919): “El Dolmen de Matarrubilla (Sevilla)”. Memorias de la Comisión de Investigaciones Paleontológicas y Prehistóricas n. ${ }^{\circ} 26$.

ORIA, M., MANCEBO, J. FERRER, E., ESCOBAR, B., GARCIA, E., RODRIGUEZ, A., VELASCO, F., SIERRA, F., PEREZ, A., OTERO, P. (1991): El poblamiento antiguo en la Sierra Sur de Sevilla: Zona de Montellano. Sevilla.

PELLICER, M. (1986): "Neolítico". Prehistoria 1. Historia de España. Barcelona : 151-206.

PELLICER, M., ACOSTA, P. (1982): “El Neolítico Antiguo en Andalucía Occidental”. Le Néolithique Ancien Méditerranéen. Actes du Colloque International de Prehistoire. (Montpellier, 1981). Archéologie en Languedoc n.․․ spécial : 49-60.

PELliCER, M., HURTADO, V. (1987): "Excavaciones en la Mesa del Gandul (Alcalá de Guadaira, Sevilla)" Anuario Arqueológico de Andalucía 1986 II : 338-341.

PERDIGONES, L., GUERRERO, L.J. (1987): "Excavaciones de urgencia en el Peñón Gordo (Benaocaz, Cádiz)" Anuario Arqueológico de Andalucía 1985 III : 29-33.

PERDIGONES, L., MOLINA, M.I., ROJO, A. (1987): “Excavaciones de urgencia en «Carissa-Aurelia» 1986. Segunda Campaña". Anuario Arqueológico de Andalucía 1986 III : 67-74

PERDIGONES, L., MUÑOZ, A. (1987): "Excavación de urgencia en un solar de la calle Doctor Gregorio Marañón (Cádiz) en 1985". Anuario Arqueológico de Andalucía 1985 III : 55-57.

PERDIGONES, L., MUÑOZ, A., BLANCO, F.J., RUIZ, J.A. (1987): "Excavaciones de urgencia en la Base Naval de Rota (Puerto de Santa María, Cádiz)". Anuario Arqueológico de Andalucía 1985 III : 74-80.

PERDIGONES, L., MUÑOZ, A., TROYA, A. (1987): "Excavaciones de urgencia en un solar de la calle Ciudad de Santander esquina Avda. Andalucía (Cádiz)". Anuario Arqueológico de Andalucía 1986 III : 41-44.

PEREZ, A. (1986): “La ocupación prehistórica de la Peña de Arias Montano (Alajar, Huelva): Contribución a su estudio". Primeras Jornadas del Patrimonio Histórico-Artístico. Sierra de Huelva (Almonaster La Real, Huelva. 1985) : 77-106.

(1987): Carta Arqueológica de los Picos de Aroche. Higuera de la Sierra (Huelva).

PEREZ, A., LORENZO, J.P., PEREZ, R. (1988): "Dólmenes de la cabecera del río Tinto en Huelva y Sevilla". Huelva en su Historia 2 : 23-56.

PEREZ, A., RIVERO, E., CRUZ-AUÑON, R. (1990): "Estudio estratigráfico de la Cueva de la Mora (Jabugo, Huelva)". Huelva en su Historia 3 : 11-45.

PEREZ, J.A., VARGAS, J.M., ROMO, A.S., SIERRA, F. (1990): “Carta Arqueológica del Término Municipal de Osuna (Sevilla)”. Anuario Arqueológico de Andalucía 1987 III : 607-611.

PIÑON, F. (1986): "El Neolítico de Huelva". Huelva y su Provincia. II Sevilla.

(1987a): "La Edad del Cobre en el Suroeste de la Península Ibérica: Claves de la periodización de un proceso". El Origen de la Metalurgia en la Península Ibérica I. Papeles de Trabajo: Arqueología. Instituto Univ. "José Ortega y Gasset". Univ. Comp. Madrid : 40-64.

(1987b): "El Cabezo de los Vientos, La Zarcita (Santa Bárbara de Casa): Un poblado calcolítico fortificado en el N.E. de la provincia de Huelva. Campaña de excavaciones de 1985". Anuario Arqueológico de Andalucía 1985 II : 272-278. 
(1987c): "Los Vientos de la Zarcita (Santa Bárbara de Casa, Huelva). Campaña de excavaciones". Anuario Arqueológico de Andalucía 1986 II : 317-324.

(1988): "El poblamiento Neolítico de la orla litoral onubense: estado de la cuestión". I Congreso Internacional "El Estrecho de Gibraltar" Tomo I. (Ceuta, 1987) : 221-253.

(1989): "El proceso de poblamiento del sector noroccidental de la provincia de Huelva durante la Edad del Cobre". III Jornadas de Patrimonio Histórico-Artístico de la Sierra de Huelva : 91-156.

PIÑON, F., BUENO, P. (1985): "Estudio de las colecciones de materiales procedentes de La Dehesa (Lucena del Puerto) y El Judío (Almonte). Testimonios sobre la ocupación neolítica del litoral onubense". Huelva Arqueológica VII : 107-159.

(1988): "El Neolítico en el suroeste peninsular". López, P. (ed.): El Neolítico en España. Madrid : 22 1-249.

PONSICH, M.

(1974): Implantation rurale antique sur le Bas-Guadalquivir. Tomo II. Casa de Velázquez. Madrid

QUINTERO, P.

(1935): "Excavaciones en Cádiz". Memorias de la Junta Superior de Excavaciones y Antigüedades. n.o 134. Madrid.

RAMOS, J.

(1990): "Talleres líticos de la Prehistoria Reciente de Cádiz". Il Congreso Internacional "El Estrecho de Gibraltar". Ceuta (En prensa).

RAMOS, J., GILES, F., GUTIERREZ, J.M., MATA, E., MOLINA, M.I. (1989): “El Taller de Buenavista, en la Sierra de San Cristóbal, El Puerto de Santa María. Comprobación de una facies de talleres líticos del Calcolítico y Bronce en la Bahía de Cádiz". Revista de Historia de El Puerto n.ำ 3 : 11-36

RAMOS, J., GILES, F., GUTIERREZ, J.M., SANTIAGO, A., BLANES, C., MATA, E., MOLINA, M.I. (1989): "Aproximación tecnológica a la transición Neolítico- Calcolítico. El taller de Cantarranas (El Puerto de Santa María)". Primer Coloquio de Historias Locales. Cádiz (En prensa).

RAMOS, J., SANTIAGO, A., MOLINA, M.I., MATA; E., GONZALEZ, R., AGUILERA, L., GUTIERREZ, J.M. (1989): “Arqueología en Jerez. Primera aproximación al estudio de las industrias líticas de su Prehistoria Reciente". Cuadernos de Divulgación n." 3. Biblioteca de Urbanismo y Cultura. Jerez de la Frontera, Cádiz.

RAMOS, J. SANTIAGO, A., GUTIERREZ, J.M., MATA, E. (1990): "Talleres e industrias líticas postpaleolíticas del Occidente de Andalucía. Informe de la campaña de Prospecciones en Jerez de 1989". Anuario Arqueológico de Andalucía 1990. (En prensa).

RAMOS, J., SANTIAGO, A., MOLINA, M.I., MATA, GUTIERREZ, J.M. (1989): "Fuensanta (Arcos de la Frontera). Un gran taller del Calcolítico y Bronce en la Presierra del Noreste de Cádiz". Primer Congreso de Historias Locales. Cádiz (En prensa).

RAMOS, J., SANTIAGO, A., ROMERO, J.L., ALMAGRO, A., GUTIERREZ, J.M., MATA, E. (1990): "Cuarti1lo. Un asentamiento neolítico al aire libre en el curso bajo del Guadalete". Páginas. Revista de Humanidades n.. 4. Jerez de la Frontera, Cádiz : 66-87.

RAMOS, J., SANTIAGO, A., VALVERDE, M.‥, GILES, F., GUTIERREZ, J.M., MATA, E. (1990): "Garrapilo (Jerez). Un modelo de explotación lítica de la cobertera holocénica del río Guadalete". Butlletí de l'Associació Arqueológica de Castelló. "Llansol de Romani" n." $8: 21-34$

RENFREW, C. (1976): "Megaliths, territories and populations". S.J. De Laet (ed.): Acculturations and Continuity in Atlantic Europe. Ghet, $1975: 298-320$.

RIVERO, E., CRUZ-AUÑON, R., GARCIA, F.M (1988): "Nuevos datos sobre el Megalitismo onubense: Necrópolis de Berrocal". Huelva en su Historia 2 : 11-42.

RODRIGUEZ, I. (1984): "El Eneolítico de la Vega de Carmona: Aplicación de un modelo de gravedad". Habis $15: 283-307$

RODRIGUEZ DE GUZMAN, S., CACERES, P. (1991): "Prospección Arqueológica Superficial en el Término Municipal de Aznalcázar (Sevilla)”. Anuario Arqueológico de Andalucía 1988 III : 377-381.

ROMERO, C. (1990): "Marinaleda". Anuario Arqueológico de Andalucía 1987 I : 57.

ROMO, A.S., SIERRA, F., VARGAS, J.M. (1991): "Prospección Arqueológica Superficial en el Término Municipal de Gilena (Sevilla)". Anuario Arqueológico de Andalucía 1988 III : 306-314. 
ROSA, D. de la, MOREIRA, J.M. (Coordinadores) (1987): Evaluación de recursos naturales de Andalucía. Agencia de Medio Ambiente. Sevilla.

RUFETE, P., GARCIA, C., GARCIA, J.M. (1988): "Evidencias calcolíticas y campaniformes en el Término de Paterna del Campo (Huelva)". Huelva en su Historia 2: 119-126.

RUIZ, M.M. (1985): Carta Arqueológica de la campiña Sevillana. Zona Sureste I. Sevilla.

RUIZ FERNANDEZ, J.A. (1987): "Informe de las excavaciones de urgencia. Pago de Cantarranas-La Viña-El Puerto de Santa María". Anuario Arqueológico de Andalucía 1986 III : 95-100.

RUIZ FERnANDEZ, J.A., RUIZ GIL, J.A. (1989): "Calcolítico en el Puerto de Santa María". Revista de Arqueología $94: 7-13$.

RUIZ GIL, J.A. (1987): "Prospecciones Superficiales en la zona del Término Municipal de El Puerto de Santa María (Cádiz). 1985". Anuario Arqueológico de Andalucía 1985 II : 101-102.

RUIZ GIL, J.A., RUIZ FERNANDEZ, J.A. (1987): "Excavaciones de urgencia en El Puerto de Santa María, Cádiz". Revista de Arqueología 74 : 5-12.

RUIZ, D. (1975a): "Cerámicas del Bronce del poblado de Valencina de la Concepción (Sevilla): los platos". Cuadernos de Prehistoria y Arqueología de la Universidad Autónoma de Madrid 2 : 123-150.

(1975b): "Cerámicas del Bronce del poblado de Valencina de la Concepción (Sevilla)". Madrider Mitteilungen $16: 80-110$.

(1983): "El yacimiento de la Edad del Bronce de Valencina de la Concepción (Sevilla), en el marco cultural del Bajo Guadalquivir". Actas I Congreso Historia de Andalucía. Prehistoria y Arqueología. (Córdoba, 1976) : 183-208.

(1986): “Aportación al análisis de los inicios de la presencia fenicia en Andalucía sudoccidental, según las excavaciones del Cabezo de San Pedro (Huelva), San Bartolomé (Almonte, Huelva), Castillo de Doña Blanca (Puerto de Santa María, Cádiz) y El Carambolo (Sevilla)". Homenaje a L. Siret. (Cuevas del Almanzora, 1984). Sevilla : 537-556.

(1988): "El Castillo de D” Blanca". Revista de Arqueología 85 : 36-48.

RUIZ, D. Y FERNANDEZ, J. (1986): "El yacimiento metalúrgico de época tartésica de San Bartolomé de Almonte (Huelva)". Huelva Arqueológica VIII (Dos vol.).

SALAS, J. de la A., BARRIONUEVO, F. (1990): "Dólmenes de la Provincia de Sevilla". Revista de Arqueología $109: 6-10$.

SANTANA, I. (1990): "Informe acerca del hallazgo de restos arqueológicos en el Término Municipal de Utrera (Sevilla)". Informe Técnico de la Delegación Provincial de Cultura de Sevilla.

(1991): "Excavación de urgencia de una estructura siliforme de enterramiento en el Cortijo de M." Luisa (Cantillana, Sevilla)". Anuario Arqueológico de Andalucía 1988 III : 283-285.

SANTIAGO, J.M. (1983): "Notas sobre una prospección arqueológica superficial en el Cerro de Las Motillas". Speleon 26-27. Centro Excursionista de Catalunya. Barcelona : 129-145.

TOSCANO, M. (1987a): "Prospección Arqueológica Superficial en Alcalá de los Gazules". Anuario Arqueológico de Andalucía 1986 II: 143.

(1987b): "Inventario de los yacimientos arqueológicos y lugares de interés histórico y etnográfico de la Sierra de Grazalema". Boletín del Museo de Cádiz IV : 33-46.

VALLESPI, E., RAMOS, J., CASTIÑEIRA, J.(1988): "Talleres líticos del Calcolítico y Bronce en la Sierra de Huelva y Andévalo". Huelva en su Historia 2 : 127-146

VALLESPI, E., RAMOS, J., PEREZ, F. (1988): "Conjunto de sílex calcolítico de la Sierra de Aracena (Huelva)". I Congreso Nacional de la Cuenca Minera de RíoTinto. (RíoTinto, Huelva). : 755-785.

VELASCO, F.J., ESCOBAR, B., ORIA, M., MANCEBO, J., FERRER, E., GARCIA, E., RODRIGUEZ, A., PEREZ, A.M., SIERRA, F. (1990): "Avance a la Carta Arqueológica de Montellano (Sevilla)" Anuario Arqueológico de Andalucía 1987 II : 151-156.

(1991): "Avance de la Carta Arqueológica de la zona de Montellano II". Anuario Arqueológico de Andalucía 1988 II : 131-135.

VERA, M., FERNANDEZ, R. (1991): "Prehistoria de Morón de la Frontera (I): La distribución de la población en el sector suroriental". Desde la Frontera. Revista de Temas Moronenses n.․․ 2 : 171-191. 